Article

\title{
Choice of the Optimal Design and Operation of Multi-Energy Conversion Systems in a Prosecco Wine Cellar
}

\author{
Davide Pivetta ${ }^{1}$ (D), Sergio Rech ${ }^{2}$ (D) and Andrea Lazzaretto ${ }^{1, * \mathbb{D}}$ \\ 1 Department of Industrial Engineering, University of Padova, 35131 Padova, Italy; \\ davide.pivetta@studenti.unipd.it \\ 2 Veil Energy Srl, 35010 San Pietro in Gu, Padova, Italy; s.rech@veil-energy.eu \\ * Correspondence: andrea.lazzaretto@unipd.it
}

Received: 3 September 2020; Accepted: 25 November 2020; Published: 27 November 2020

check for updates

\begin{abstract}
Despite the high energy consumption of wine making processes, little efforts have been spent so far, both at the industrial and scientific level, to search for alternative energy systems in wine cellars. In fact, almost all the existing cellars take electricity from the grid and burn natural gas or other fossil fuels to fulfil their energy demands. This paper analyses the energy demands of a real Prosecco wine cellar in the North East of Italy, which can be considered as a "reference" cellar for dimensions and wine production. The goal is to find the best energy conversion system in terms of maximum profits, efficiency and share of renewable energy utilization. Four alternative design configurations are proposed, and each one optimized considering the three objectives. Results show that a $35 \%$ gain in the maximum profits is obtained by including a natural gas fueled CHP internal combustion engine and an absorption chiller. This configuration is also the best one to achieve the maximum efficiency (61\%), resulting in 18\% reduction of primary energy consumption. Conversely, the utilization of a biomass boiler and an absorption chiller allows maximizing the share of renewable energy consumption, which is about $35 \%$ considering the existing availability of biomass from pruning harvesting and the relative limited surface available for photovoltaic generation. This option may become economically interesting when the price of natural gas increases of at least $50 \%$.
\end{abstract}

Keywords: wine cellar; combined heat and power (CHP) technologies; energy system modelling and optimization; environmental sustainability; renewable energy technologies

\section{Introduction}

Italy is the major wine producer in the world and the Italian wine sector is growing up in terms of cultivated hectares and revenues, thanks to the increase of exported products, mainly, to US, $\mathrm{UK}$, and Germany. The wine-making process is energetically expensive (5-16 kWh per hectoliters of wine), and the electricity consumption is commonly predominant over the thermal one. This is because electricity is required in most steps of the process, such as grapes treatment, must handling and wine bottling (electricity is converted into mechanical power), and refrigeration during fermentation, sparkling and conservation of wine (electricity is converted into cooling power). In particular, cooling is usually provided (at the different temperatures fixed by the wine-making processes) exclusively by a set of compression chillers, bringing the electricity demand up to $90 \%$ of the total energy consumption [1-3]. This strong imbalance between electrical and thermal demands generally prevents from considering $\mathrm{CHP}$ units in the energy system of the cellar. In fact, in most of the several wine cellars in Italy the electricity is taken from the national grid and the thermal energy is generated by boilers fueled by natural gas available from the distribution network. This traditional solution offers a great deal of room for improvement in economic, energy and sustainability terms. 
In the literature, two main approaches have been proposed to obtain higher efficiency and sustainability in the wine-making process: (i) searching for more efficient steps/units in the wine-making process (ii) using the biomass deriving by pruning residues.

(i) The high energy consumption of cellars and the increasing costs of energy have been the driving force in the search for higher energy efficiency in the wine-making process. Several studies were performed in the literature, all of which analyze specific steps/units of the wine production chain. Some of these studies focuses on the features of cellar buildings to improve the efficiency of the wine production process without affecting the wine quality. Santolini et al. [4] investigated the influence of temperature, humidity and air velocity on the quality of the wine ageing process, and optimized the design of the ventilation system using CFD modelling. Nocera et al. [5] analyzed the optimal hygrothermal conditions for wine cellar to guarantee high performance of the ageing process. Arredondo-Ruiz et al. [6] proposed a review of the design and features of ageing rooms to find the designs that promote a more efficient use of the cooling and ventilating systems. Benni et al. [7] studied different configurations and materials for wine storage buildings to provide guidelines for an energy-efficient choice of building materials and technical solutions. Other studies are focused on the energy requirements of the wine-making process. Malvoni et al. [8] evaluated the overall energy consumption of an Italian winery located in Southern Italy, showing that most of the primary energy consumption is due to the generation of cooling streams (necessary in many stages of the wine-making process). J. Fuentes-Pila et al. [9] dealt with different techniques and technologies to reduce the environmental impact and improve the sustainability of the wine-making process. In their very wide study, they collected and organized the energy consumptions data of many cellars located in the four major wine-making countries of Europe (Italy, France, Spain and Portugal), taken from the Tesla project [2]. Also the Italian national Higher Institute for Environmental Protection and Research institute (ISPRA) [10] usually collects energy consumption data of wine cellars in the Italian territory (see, e.g., [3]). De Bortoli [11] and Paolino [12] analyzed in detail the design of machineries utilized in a traditional wine cellar. Catrini et al. [13] proposed a new procedure to obtain reliable profiles for cooling needs of medium-scale wine cellars. The final goal is to have a precise basis for the assessment of the energy saving that can be achieved by installing more efficient compression chillers. Gómez-Lorente et al. [14] evaluated the potential reduction in electricity costs deriving from the installation of photovoltaic technologies in wine cellars. Results show that an intensive use of photovoltaic in Spanish cellars may reduce the electrical power costs from $4 \%$ to $36 \%$ depending on the cellar size. Moreover, the maximum achievable share of renewable energy utilization result to be $57 \%$ without considering the use of batteries. This value was obtained without considering a limit to the area availability for the solar power station. Finally, an important study of ENEA [1] collected data of the wine production chain through a volunteer survey, which involved several small and medium enterprises and Producers Consortia to check the current state of the use of resources and identify key elements for efficiency. The report presents information on best practices and technological innovations.

(ii) Different studies in the literature highlight the importance of using properly the biomass deriving by pruning residues. Energy recovery from these residues is a good option to limit the utilization of fossil fuels. Commercial technologies of biomass management have reached a high level of maturity with a progressive reduction of costs. Fernández-Puraticha et al. [15] evaluated the main energy characteristics of pruning residues (calorific value and ashes content), and showed that the conversion into woodchips instead of pellets results in lower costs and carbon footprint, because of the lower amount of energy for production and transportation. Spinelli et al. [16] and Albergucci [17] demonstrated that pruning recovery is not always economically convenient, but generates significant advantages on air quality and landscape preservation. However, the collection of pruning residues is energetically and economically convenient in north east of Italy, in which the analyzed cellar is located, due the favorable morphologic characteristics of 
the territory and the great amount potentially available. These studies evaluate the amount of biomass per cultivated hectare of vineyards, and analyze the chipping and pressing processes to increase the biomass density, emphasizing the positive qualities of the obtained biomass but also the disadvantages and costs of this system. Bacenetti [18] compared in terms of environmental impact two energy uses of pruning residues (generation of heat and generation of heat and cold) as alternatives to the common practice of chopping and leaving the residues on the soil (base case). Compared to the base case, the proposed alternative uses lead to the reduction (from 1.6 to 9.5 times) of the environmental impact indicators belonging the categories of climate change, ozone depletion, acidification and freshwater eutrophication but an increase (up to 38 times) of the indicator categories strongly related to the wood combustion, such as particulate matter and photochemical oxidant emissions. Zanetti et al. [19] analyzed the properties of different shapes of vine biomass and their behavior during combustion in domestic stoves and industrial boilers, demonstrating that the former cannot comply with the EN ISO 17225 International Standards. Pizzi et al. [20] tested vine pruning pellets in a $150 \mathrm{~kW}$ boiler, measuring the total suspended particles (TSP), $\mathrm{CO}$ and $\mathrm{NO}_{\mathrm{X}}$ emissions. They also compared the emissions deriving from combustion of these pellets in a boiler with those of the direct open-field combustion of pruning residues. The latter are up to 120 times higher in terms of $\mathrm{CO}$ and 30 times higher in terms of TSP. Avoiding open field combustion and increasing the energy production from renewable sources, results in a significant reduction of environmental pollution. Picchi et al. [21] demonstrated the excellent performances of electrostatic filters to reduce total fly ash emissions of boilers specifically tailored for biomass with high content of ash. Also Zanetti et al. [19], Pizzi et al. [20] and Picchi et al. [21] demonstrate the lower costs of woodchips compared to pellets in spite of the slightly lower performances in terms of combustion efficiency and emissions of pollutants.

From this literature survey it is clear that, though wine-making processes involve mature technologies, and many studies discuss features and performance of single energy units, there is still a lack of studies about the design and optimization of the total energy system of wine cellars.

This paper fills this knowledge gap by considering the whole energy system of a Prosecco wine cellar in the north east of Italy, which can be considered as a reference cellar for dimensions and total wine production over the year. The goal is to find the best energy conversion system in terms of maximum profits, efficiency and share of renewable energy utilization.

Four alternative design configurations are proposed, and the operation of each one optimized considering the three objectives starting from detailed estimates of the energy consumptions (electricity, heat and cooling), and using a mixed-integer linear programming (MILP) optimization approach. The MILP approach is widely used in the literature (see, e.g., [22-25]) dealing with conceptually similar problems, where several energy conversion units work together to satisfy the time variable demands of different forms of energy. Two of the alternative energy system configurations of the cellar involve the partial replacement of the existing compression chillers with absorption ones to obtain a more balanced ratio between electric and thermal demands, and so allowing an efficient use of a CHP unit and an increase of the renewable share (by burning the pruning residues in a biomass boiler). This is an innovation in the field of wine production, which has been introduced only in few real applications, but still not thoroughly analyzed in the scientific literature. Each configuration is also evaluated from the economic point of view, estimating the investment and operation costs of each conversion unit and the revenues deriving from selling the excess of generated electricity, considering real costs of commercial devices and present prices of energy. This information allows obtaining good estimates of profits to calculate the net present value and payback period of each configuration. The combination of these indexes with the energy performance are finally used to get reliable indications for the correct choice of the best energy system configuration. 


\section{Wine Making Process and Associated Energy Demands}

A medium-sized prosecco wine cellar placed in the north east of Italy is taken as reference case to evaluate costs, efficiency and degree of sustainability of the multi-energy system that must meet the energy demands (electrical, thermal and cooling) of the wine-making process.

The assessment of the actual energy demands of the cellar is the first fundamental step for any proper energy audit. In the wine-making sector this is not an easy task because, as highlighted also in [13], the energy demands are strongly variable on seasonal and daily bases, and a direct measurement of the consumption of the many involved devices would be too expensive (the only available information on consumptions usually derives from monthly or annual bills). To this end, the main steps of the wine production have been deeply analyzed (Section 2.1) to obtain as accurate as possible consumption profiles of each step, and therefore of the entire process (Section 2.2). Compared to the direct measurement of the energy consumption this approach may not be able to reconstruct the exact instantaneous demand of each process, but certainly provides an accurate picture in average terms. Moreover, it could also be applied in different cellars, where the available data are reasonably of the same type of those of the reference winery considered here.

\subsection{Wine-Making Process}

Wine-making involves many different processes which nowadays are mechanized and industrialized to have high production capacities of wine per day. According to the quality and type of wine, there are significant variations in energy requirements both in terms of quantity and variability during the year.

Thus, an in-depth knowledge of the involved processes is necessary to estimate their consumptions. The main processes are described in the following:

- Receipt, rasping and pressing of grapes. The collected grapes are first sent to the wine cellar to be analyzed chemically. Thereafter, they are rasped and pressed to obtain a pulp rich in juice (must) and the stalks, the latter are removed from the production cycle and can be used by distilleries or converted into biomass fuels. If grapes are used for white wine production (as in the present paper), grape peelings are separated from the pulp. On the contrary, in red wine production, peelings take part to the next processes. Other residues are drained from the juice, and the remaining pulp and juice filtered again and cooled. In this first step, machineries use electrical power engines for handling mechanically the matter. Chemical compounds are introduced in the cycle, for example $\mathrm{SO}_{2}$, absorbents, tartaric acid, and citric acid [1].

- Alcoholic fermentation. Thanks to the addition of yeasts and chemical activators, sugar contained in the pulp and must is converted into ethyl alcohol, carbon dioxide and thermal energy. In order to keep a good quality of the final product, process temperature is kept constant by chillers to avoid the production of acetic acid $\left(18-20^{\circ} \mathrm{C}\right.$ for white wines and $25-28^{\circ} \mathrm{C}$ for red wines). Must and pulp are mechanically moved to promote contacts between yeast and must, avoiding in any case the oxygen introduction. The $\mathrm{CO}_{2}$ produced in this phase can be smartly used in other processes in the cellar.

- Pressing and malolactic fermentation. The fermented liquid is sent to tanks for a second fermentation in which malolactic acid (naturally contained in grapes) is converted by lactic bacteria into lactic acid and $\mathrm{CO}_{2}$. This process reduces the $\mathrm{pH}$ of the liquid and increases the contents of polyphenol and glycerol, making the wine taste better. Process temperature is kept constant by chillers at the optimal working temperature for lactic bacteria $\left(20-23^{\circ} \mathrm{C}\right)$ [1]. Only in the production of red wine, before this second fermentation process pulp and peelings are pressed again (in general the higher the pressing pressure in this step, the lower the quality of wine).

- Bottling and conserving. After malolactic fermentation the liquid, that is full-fledged wine, requires some additional processes before being aged or bottled. Sparkling wines are processed into an autoclave keeping pressure and temperature at specified values (5-10 bar and $\left.14-18{ }^{\circ} \mathrm{C}\right)$ 
to convert a part of the residual sugar (or sugar added before this phase) into gaseous carbon dioxide. This is the base principle of Charmat method used to produce most of the white sparkling wine in the north-east of Italy, like Prosecco. Conversely, still wines are stabilized and clarified by adding chemical agents. In making high quality wines (usually red ones), at this step wine could be transferred into wood barrels for aging before bottling. In this way, wine assumes special tastes and increases its quality. Bottling plants require a great amount of electricity for their mechanized processes. Moreover, water steam is used to disinfect bottles before filling and inert gases are used to fill the empty space between wine level and plug, preventing the oxidation and ensuring conservation of wine [1].

Typical values provided in the literature for energy consumptions, rated powers, and types of machines involved in each process are taken as reference here (Table 1). They relate to a medium-size cellar located in TESLA analyzed countries (Italy, Portugal, France, and Spain). Note that the cooling duties are expressed in terms of electric energy consumption because they are usually satisfied by compression chillers (rated in terms of installed electric power).

Table 1. Size and consumption of machineries used in wine-making process [1].

\begin{tabular}{|c|c|c|c|c|c|}
\hline $\begin{array}{c}\text { PROCESS } \\
\text { (Chronological Order) }\end{array}$ & $\begin{array}{l}\text { Machines Standard } \\
\text { Technology }\end{array}$ & $\begin{array}{c}\text { Installed } \\
\text { Electric Power } \\
(\mathbf{k W})\end{array}$ & $\begin{array}{c}\text { Electric } \\
\text { Energy } \\
\text { Consumption } \\
(\mathbf{k W h} / \mathrm{hl})\end{array}$ & $\begin{array}{c}\text { Installed } \\
\text { Thermal } \\
\text { Power (kW) }\end{array}$ & $\begin{array}{l}\text { Thermal } \\
\text { Energy } \\
\text { Consumption } \\
(\mathrm{kWh} / \mathrm{hl})\end{array}$ \\
\hline Grapes receiving & $\begin{array}{l}\text { Receiving hoppers, } \\
\text { screw mechanisms and } \\
\text { electric engines }\end{array}$ & 57 & 0.55 & 0 & 0 \\
\hline Rasping and pressing & $\begin{array}{l}\text { Mechanical rasping, } \\
\text { rollers, and } \\
\text { electrical engines }\end{array}$ & 64 & 0.55 & 0 & 0 \\
\hline Alcoholic fermentation & $\begin{array}{l}\text { Chillers and } \\
\text { electrical engines }\end{array}$ & 276 & 5 & 0 & 0 \\
\hline $\begin{array}{l}\text { Pressing and malolactic } \\
\text { fermentation }\end{array}$ & $\begin{array}{l}\text { Chillers, pumps, and } \\
\text { electrical engines }\end{array}$ & 76 & 0.75 & 0 & 0 \\
\hline Stabilization & Chillers & 91 & 0.9 & 0 & 0 \\
\hline $\begin{array}{l}\text { Bottling and } \\
\text { conservation }\end{array}$ & $\begin{array}{l}\text { Electric engines, } \\
\text { chillers, and } \\
\text { steam generators }\end{array}$ & 102 & 1.95 & 50 & 0.5 \\
\hline Lighting & Lighting devices & 10 & 0.75 & 0 & 0 \\
\hline Auxiliary processes & $\begin{array}{l}\text { Air conditioning and } \\
\text { domestic hot water }\end{array}$ & 124 & 1.10 & 20 & 0.5 \\
\hline \multicolumn{2}{|c|}{ TOTAL } & 800 & 11 & 70 & 1 \\
\hline
\end{tabular}

\subsection{Energy Demands}

The wine-making process requires a high demand of electric, thermal, and cooling energy. The reference medium-size cellar produces more than thirty-thousand hectoliter of prosecco every year, with an energy demand in the range 5 to $16 \mathrm{kWh}$ per hectoliter of wine. To take into account seasonal and daily variations of the energy demands, the analysis of the energy system is performed considering hourly profiles of the electric, cooling and thermal demands during a whole reference year.

Different approaches are used to obtain the profiles of electric/cooling demands and thermal demand because of the different availability of data. In all cases, the main equipment/services are grouped in accordance with the production islands to which they belong in the reference cellar. This grouping is more detailed than that in Table 1 and is therefore better suited to obtain more accurate demand profiles. These approaches can be summarized as follows: 
- The profile of the electric demand (Section 2.2) is calculated starting from the monthly values of:

(i) the electricity taken from the national grid (light blue bars in Figure 1) and

(ii) the electricity produced by two photovoltaic solar stations (PV) which are installed on the available surface of the cellar roof (orange bars in Figure 1, see Section 2.2.1 for details on the PV solar stations).

- Both sets of monthly values (i) and (ii) are directly obtained as average from the electric bills of the last five year. The sum in each month of the (i) and (ii) contributions corresponds to the total electric consumption in the same month because the electricity generated from PV is completely self-consumed.

- The profiles of the cooling demands at two different temperature $\left(7^{\circ} \mathrm{C}\right.$ and $-7^{\circ} \mathrm{C}$, Section 2.2) are extracted from the electric demand since all cooling streams are generated by electrically driven chillers (compression chillers, see Section 2.2.1) in the existing energy system.

- Differently from the electric case, monthly values of the cellar thermal demand are not available. Thus, the hourly profile of the thermal demand (Section 2.2.2) is directly estimated starting from the practical observation of the overall wine-making process. The monthly values of the thermal consumption in Figure 1 (red bars) are then obtained from the hourly profile for comparison with the electric ones.

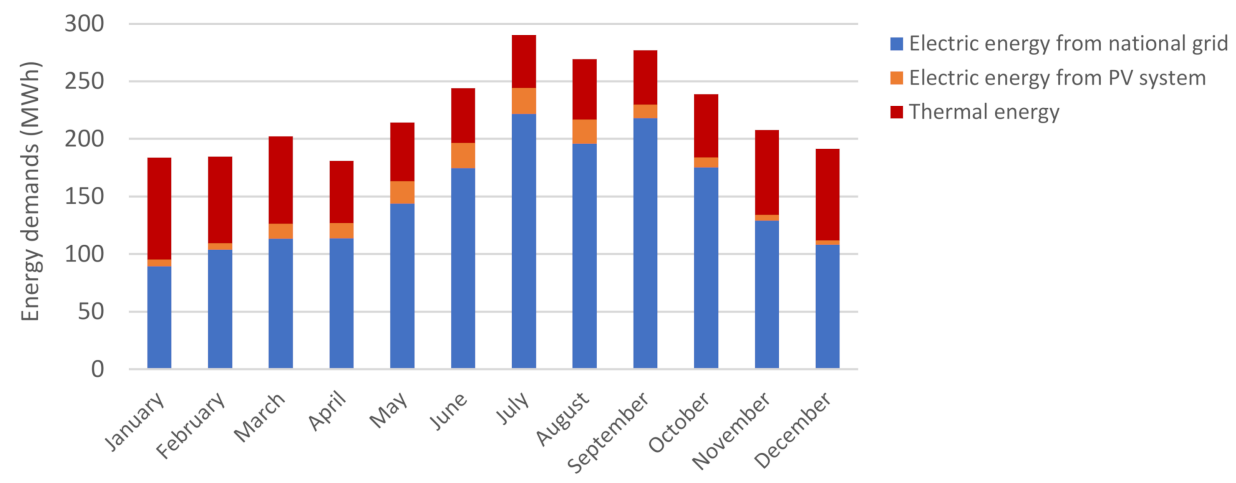

Figure 1. Monthly values of the electricity taken from the national grid, electricity generation of the photovoltaic station units and thermal energy consumption in the reference year.

The electric consumption is higher than the thermal one, especially during summertime because of the high demand for cooling of the wine production and storage processes. The thermal demand is higher in winter than in summer due to the space heating demand.

\subsubsection{Electricity and Cooling Demands}

The monthly electricity consumption in Figure 1 are "translated" into hourly demands considering the following assumptions on load profile of each group of equipment/services:

- Receiving, destemming and treading of grapes ( $R+D+T$ in Figures 2 and 3): the processes are operated for 20 days/month, $8 \mathrm{~h} /$ day. These energy demands depend on the available data of mass flow rates of grapes treated in the cellar.

- Bottling + autoclave: the total electric demand (including for cooling purposes) depends on the volume and type of produced wine (sparkling or not). The bottling and sparkling phases last the whole year except for September and October when the operators are involved in grape harvesting and subsequent processes. In the other months, bottling and sparkling phases last $8 \mathrm{~h} /$ day for 20 days/month.

- Handling + filtration: an average monthly demand is estimated for a working activity of $8 \mathrm{~h}$ per 20 days/month. 
- Compressors: an average demand is calculated for $8 \mathrm{~h} /$ day, for 20 days/month. During the rest of the day, the demand is assumed to be $5 \%$ of the nominal one to keep the air pressure in the air storage tanks constant.

- Office users: the estimate of the electric demand is based on the number of office employers and working schedule, i.e., $8 \mathrm{~h} /$ day for 20 days/month.

- Lighting: electric lighting is required during the working hours ( $8 \mathrm{~h} /$ day, 20 days/week). During $8 \mathrm{~h}$ of the other hours of the day the demand is estimated to be $20 \%$ of the working day one, during he entire year.

- Fermentation and Air-handling units: the electric consumption is mainly due to cooling demand which are concentrated in the months between June and October.

- Other: this group includes all the minor electric consumptions different from the above.

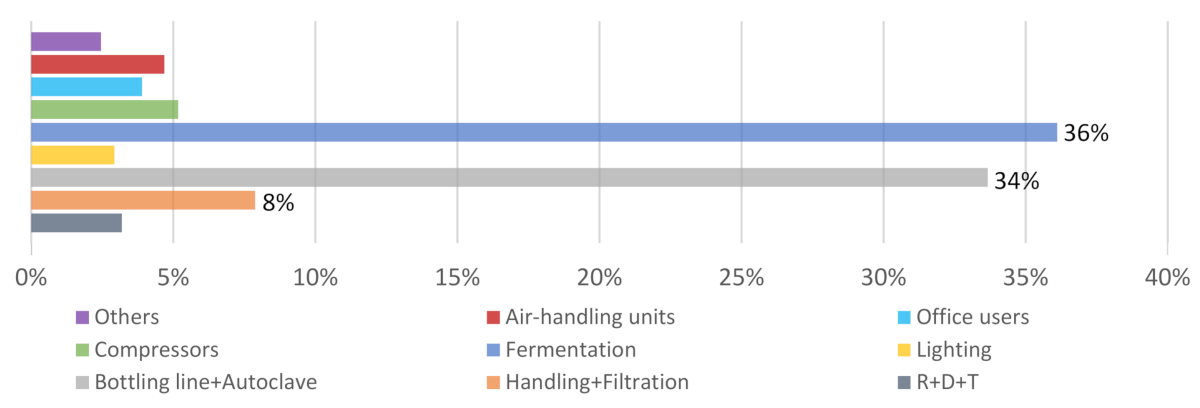

Figure 2. Shares of the total electricity demand associated with each group of equipment/services.

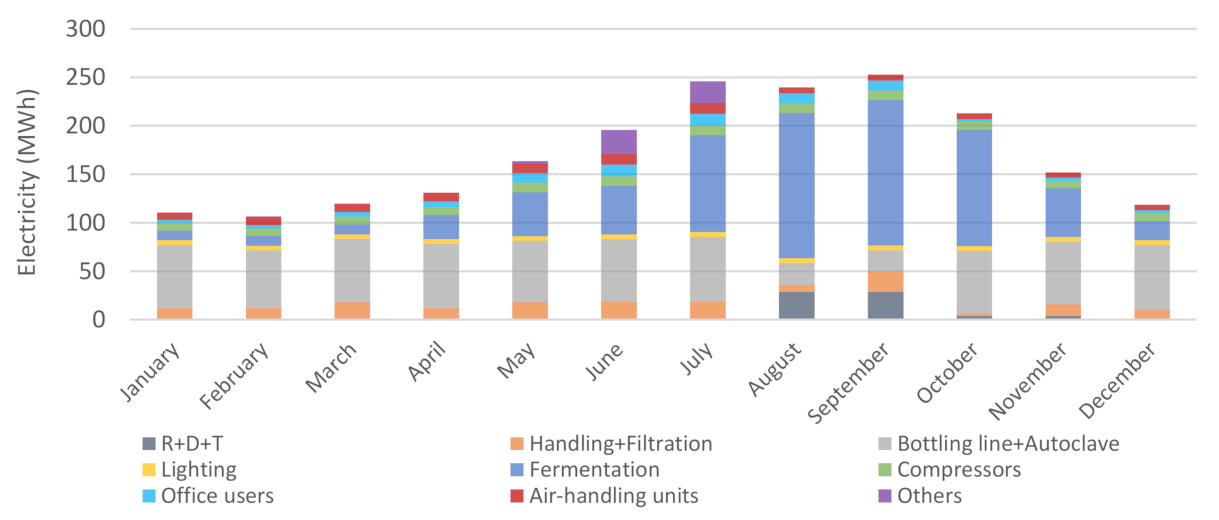

Figure 3. Breakdown of the monthly electricity demand between the considered groups of equipment/services requiring electricity.

Moreover, the shares associated with each group of equipment/services of the total electricity demand during the reference year are assumed to be equal to those shown in Figure 2. They are obtained by average values of data collected by the TESLA European project [2] for medium-to-large size cellars with a yearly wine production higher than $30.000 \mathrm{hl}$.

The main steps of the procedure followed to obtain the profile of the electrical request are as follows:

(1) The monthly demands of electricity (light blue + orange bars in Figure 1) are broken down into demands of each group of equipment/services starting from the yearly shears in Figure 2. The resulting breakdown is shown in Figure 3. It is worth noting that the bottling line has a constant energy demand over the year, whereas the electricity used to produce cooling energy is very high between June and October. In this period, cooling flows are necessary to preserve wine and keep the temperature constant (below $20^{\circ} \mathrm{C}$ ) during the must fermentation. This consumption trend was observed for other similar cellars [1-3]. 
(2) The daily demand of each group of equipment/services is estimated considering the number of working days per month.

(3) The hourly demand of each group of equipment/services is estimated considering the number of hours of operation of each group and the load in every hour (the average daily demand is multiplied by the dimensionless hourly demand).

(4) Finally, the hourly demands of all groups of equipment/services are combined hour-by-hour to obtain the searched hourly profile of electricity demand of the total cellar. The resulting profile is shown in Figure 4. The peak of consumption appears in September when grapes are conveyed to the cellar and the destemming and fermentation processes start.

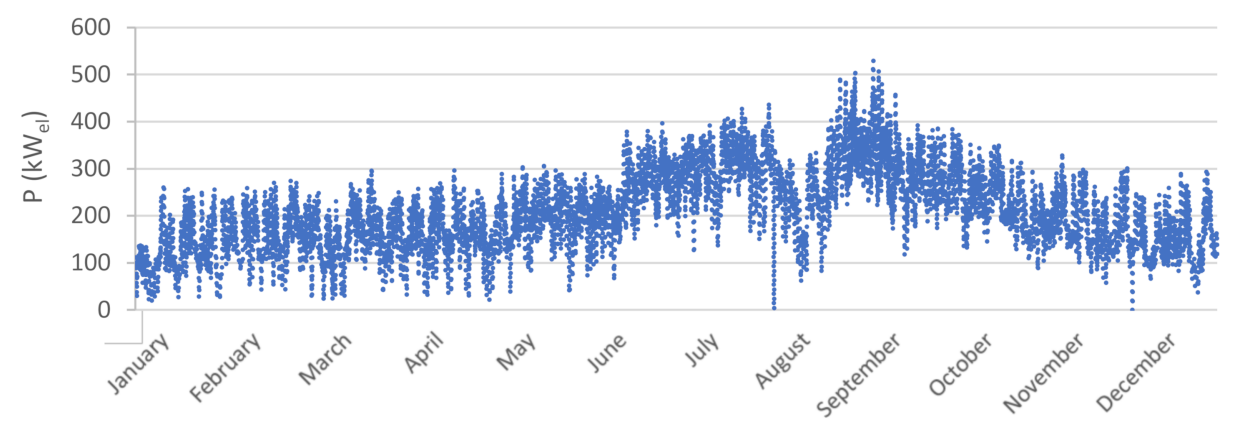

Figure 4. Chronological profile of the total electricity demand.

As described in Section 2.2, the electricity demand in Figure 4 include the requirements of the compression chillers used to generate cooling streams. This contribution is to be separated by other electricity demands to search for improved energy system configurations in which part of the cooling streams is generated by different chiller technologies.

The total cooling demand of the cellar is therefore estimated starting from typical cooling requirements of the fermentation process and the sparkling process in autoclave, in addition to those of air conditioning during summertime. In the reference cellar cooling streams are generated at two different temperatures: $7^{\circ} \mathrm{C}$ for cooling the must during fermentation, air-conditioning of offices and rooms for bottles storage; $-7^{\circ} \mathrm{C}$ for cooling during autoclave and bottling processes.

The estimate of the cooling demands is based on the following assumptions:

- Fermentation: the cooling requirement depends directly on the volume and kind (red or white) of wine. A constant average daily value of the cooling load is considered for each month. In fact, the cooling requirement that is necessary to remove the heat generated in the exothermic reactions of the fermentation process is only slightly affected by the external temperature, due to the high thermal insulation of the fermentation tanks (on the other hand, the external temperature affects the coefficient of performance of the chillers).

- Air conditioning: the cooling requirement depends directly on the volume of the conditioned spaces, climatic zone of the cellar, and the monthly variation of the external temperature, which affects the coefficient of performance of the chillers and the heat transfer between the interior of the buildings and external environment. The internal spaces are conditioned for $8 \mathrm{~h} / \mathrm{day}$ per 20 days/month. An average power of about $20 \%$ of the nominal power of the chillers is needed one hour before and one hour after the dining break to keep the desired temperature [4].

- Autoclave: the cooling requirement depends directly on the volume of sparkling white wine produced. The demand is higher during the working hours $(8 \mathrm{~h} /$ day, 20 days/month) because of the cooling requirement of the filtration and stabilization processes. These processes are not affected by the external temperature.

Figure 5 shows the chronological profiles of the cooling demands at $7{ }^{\circ} \mathrm{C}$ and $-7{ }^{\circ} \mathrm{C}$, obtained with a similar procedure to that used for the electricity profile. 


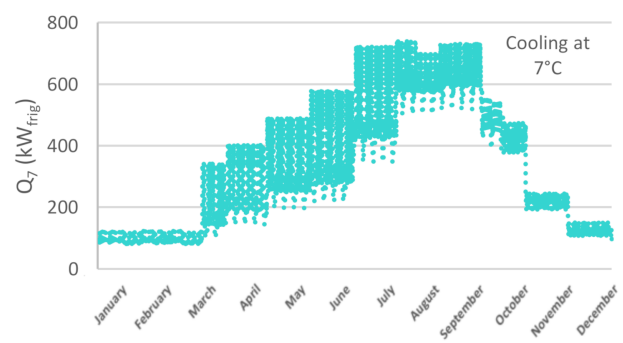

(a)

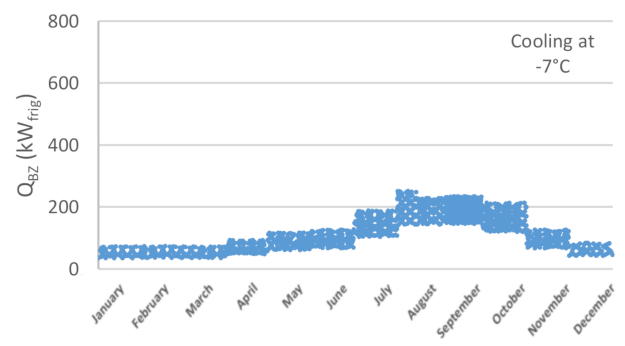

(b)

Figure 5. Chronological profiles of the cooling demand at $7{ }^{\circ} \mathrm{C}(\mathbf{a})$ and $-7^{\circ} \mathrm{C}(\mathbf{b})$.

Finally, the electricity profiles associated with the cooling demands in Figure 5 (obtained considering the characteristic maps of the existing chillers) are subtracted hour-by-hour from the total electrical demand profile (Figure 4) to obtained the profile of the electricity demand for purposes different from cooling (Figure 6).

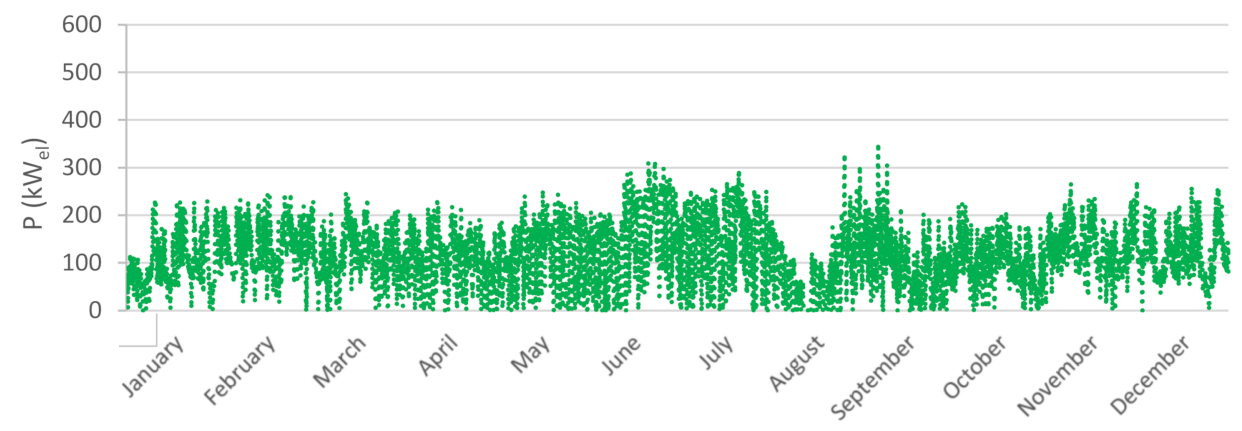

Figure 6. Chronological profile for electricity demand without cooling production.

\subsubsection{Thermal Demand}

The hourly profile of the thermal demand of the reference cellar are obtained considering different groups of equipment/services compare to the case of electricity/cooling. Moreover, the profile (Figure 7) derives directly from the practical observation of these groups of equipment/services, data collected in the analyzed wine cellar and the following scheduled set points of the equipment:

- Autoclaves: $90 \mathrm{~kW}$ (water and glycol at $\left.40{ }^{\circ} \mathrm{C}\right)$ for 2.5 days/week $(240 \mathrm{~h} / \mathrm{month})$;

- Bottling tunnel: $100 \mathrm{~kW}$ (hot water at $85^{\circ} \mathrm{C}$ ) for $10 \mathrm{~h} /$ day and 5 days/week $(200 \mathrm{~h} / \mathrm{month}$ );

- Sanitization: $80 \mathrm{~kW}$ for $3 \mathrm{~h} /$ day and 5 days/week $(60 \mathrm{~h} / \mathrm{month})$;

- Under-floor heating: $150,000 \mathrm{kWh} /$ year, thermal energy demand per hour is calculated according to the Italian law (the heating period is set between 15 of October and 15 of March) [26];

- Air handling unit, barrel and warehouses: 20,000 kWh/year, thermal energy demand per hour is calculated according to the Italian law (the heating period is set between 15 of October and 15 of March) [26]; 


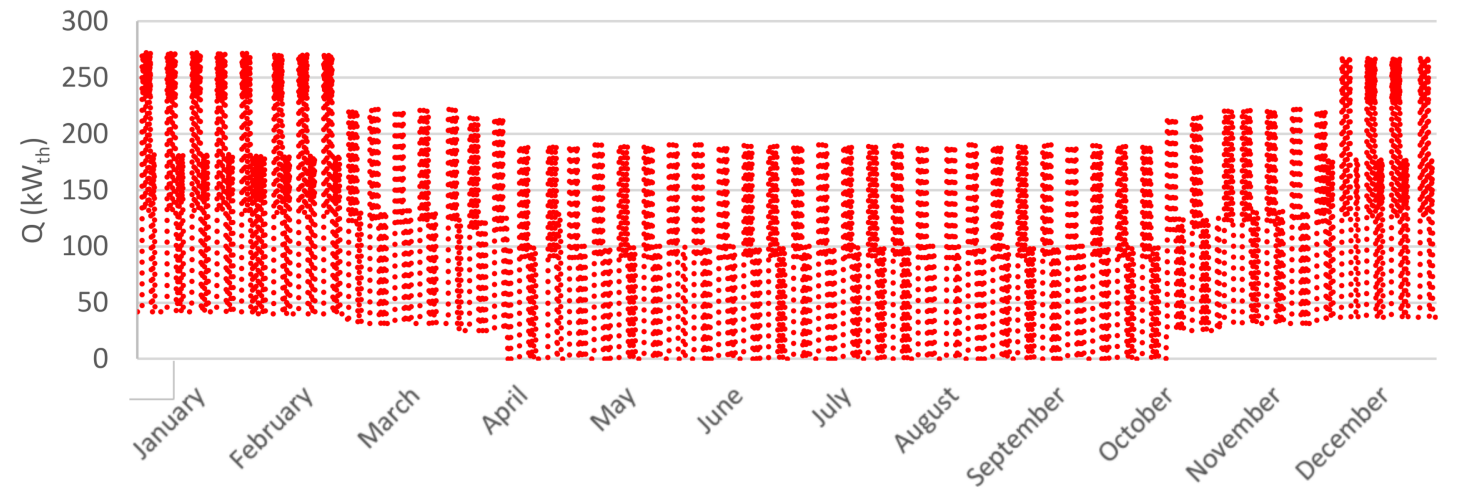

Figure 7. Chronological profile of the thermal demand.

The resulting profile in Figure 7 shows peaks of about $270 \mathrm{~kW}$ for few hours per year. The lowest demand of thermal energy (about $30 \mathrm{~kW}$ for $2000 \mathrm{~h}$ ) occurs during summer when there is no demand for space heating.

For comparison with the monthly electricity demands (Figure 3), the monthly thermal demands of the cellar are calculated and broken down in Figure 8 into demands of each group of equipment/services requiring thermal energy.

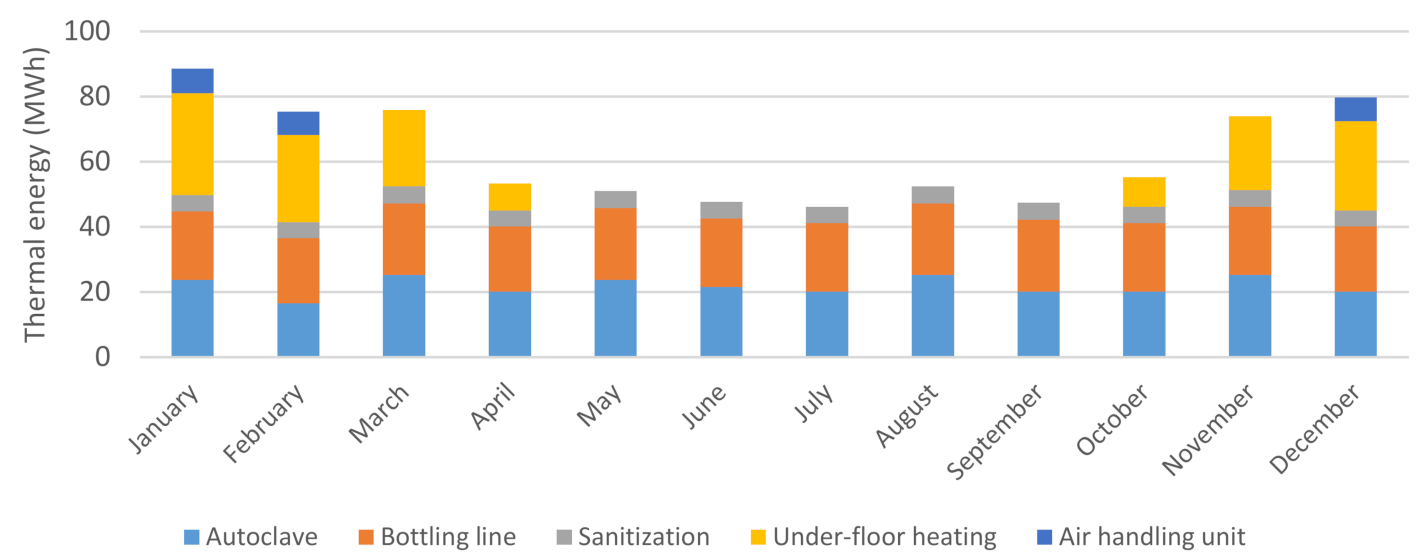

Figure 8. Breakdown of the monthly thermal demand between the considered groups of equipment/services requiring thermal energy.

\section{Description of the Existing Energy System Configuration and Proposal of Alternative Configurations}

As shown in Section 2.2, the main request of a wine cellar is electricity, approximately $90 \%$ of the total energy demand. Almost half of the electric power is used to generate cooling power with compression chillers. The remaining $10 \%$ of the required energy is thermal energy which is normally generated by a boiler powered by fossil fuels (natural gas, GPL or diesel).

This section presents the configuration of the existing multi-energy system of the reference cellar (Section 3.1). Alternative configurations are then proposed (Section 3.2) considering only mature and commercially available technologies. The aim is to reduce the environmental impact by increasing the efficiency in the use of primary energy sources and the share of renewable energy utilization. The sizes (Section 3.3) and costs (Section 3.4) of the new energy conversion units are finally evaluated according to technical and market availability. 


\subsection{Existing Energy System}

The configuration of the multi-energy system of the reference cellar (basic configuration, Figure 9) includes an industrial boiler (B,NG) coupled with thermal storage unit (TS), a set of compression chillers (A to I) and a two photovoltaic (PV) solar stations.

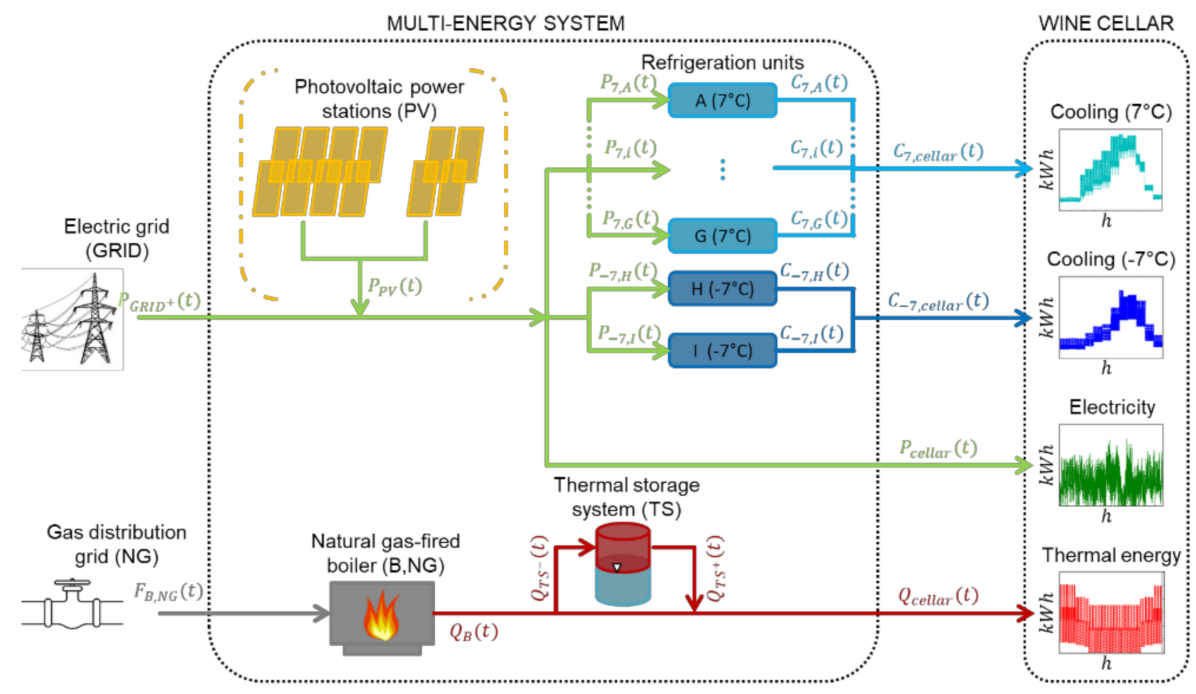

Figure 9. Basic configuration of the energy system of the reference wine cellar.

The boiler is fueled by natural gas of the national distribution grid and supplies the total thermal demand of the cellar. The thermal storage unit is used to keep the average efficiency of thermal energy production high by minimizing the partial load operation of the boiler. This unit consists of a $10 \mathrm{~m}^{3}$ thermocline tank in which hot and cool water is stored in the upper and lower part, respectively.

The cooling energy is required at two different delivery temperatures, $7^{\circ} \mathrm{C}$ and $-7^{\circ} \mathrm{C}$, and supplied by the following compression chillers (a letter identifies each unit):

- Two pairs of RHOSS TCAESY 4310 chillers (" $\mathrm{A}$ " and " $\mathrm{B}$ " for cooling at $7{ }^{\circ} \mathrm{C}$, and " $\mathrm{H}$ " and " $\mathrm{I}$ " for cooling at $\left.-7^{\circ} \mathrm{C}\right)$;

- One RHOSS TXAETY 4160 chiller (" $\mathrm{F}^{\prime}$ for cooling at $\left.7^{\circ} \mathrm{C}\right)$;

- Three Panasonic chillers (“ $\mathrm{C}$ ", “ $\mathrm{D}$ ” and “ $\mathrm{E}^{\prime}$ " for cooling at $7^{\circ} \mathrm{C}$ );

- One VENCO chiller (“G” for cooling at $7{ }^{\circ} \mathrm{C}$ ).

The photovoltaic solar stations have peak powers of $100 \mathrm{~kW}$ and $50 \mathrm{~kW}$ and are installed on the roof of the cellar. For simplicity, the electricity demand of the cellar is considered here as the difference between the total electricity demand and PV generation $\left(P_{P V}(t)\right.$ in Figure 9). This is because the latter depends only on external (weather) conditions and is a relatively small fraction of the total demand (Figure 1). This simplifying hypothesis does not affect significantly the accuracy of the estimate of the energy generated by all the alternative configurations of the energy system.

The demand analysis in Section 2.2 shows that the PV technology is particularly suitable for application in wine cellars, as the daily (daylight hours) and seasonal (summer) peaks of electricity demand corresponds to the peak of the solar radiation. However, the existing PV stations already occupies all the available roof surface of the considered cellar and there is not sufficient availability of surface area near the cellar to consider a ground mounted installation. Accordingly, the installation of additional PV modules is not considered here as a possible option to increase the share of renewable energy in the cellar energy system. The annual average share of renewable energy utilization (ratio between the annual consumption of primary energy from renewable sources and the total annual consumption of primary energy) in the reference cellar is $18 \%$, considering the contribution of both 
the PV and the average share of electricity production from renewables in the Italian electric systems (19.4\%, see Section 4.2.3).

\subsection{Proposal of Alternative Design Configurations}

Four new design configurations are proposed as alternative to the basic configuration of the cellar in Figure 9. Each configuration corresponds to the addition to or substitution of one or more energy conversion units included in the basic configuration. The final target is improving the energetic, economic, and environmental performances for the same duty of the cellar (Section 2.2).

The four configurations correspond to the:

1. Addition of a combined heat and power system (CHP) based on a natural gas-fired internal combustion engine (ICE) (Figure 10).

2. Addition of the same CHP system of point 1 plus an absorption chiller (AB) (Figure 11).

3. Substitution of the existing natural gas-fired boiler (B,NG in Figure 9 ) with a boiler fed by vineyard pruning residues (B,BM) (Figure 13).

4. Same substitution of point 3, and addition of an absorption chiller (AB) (Figure 12).

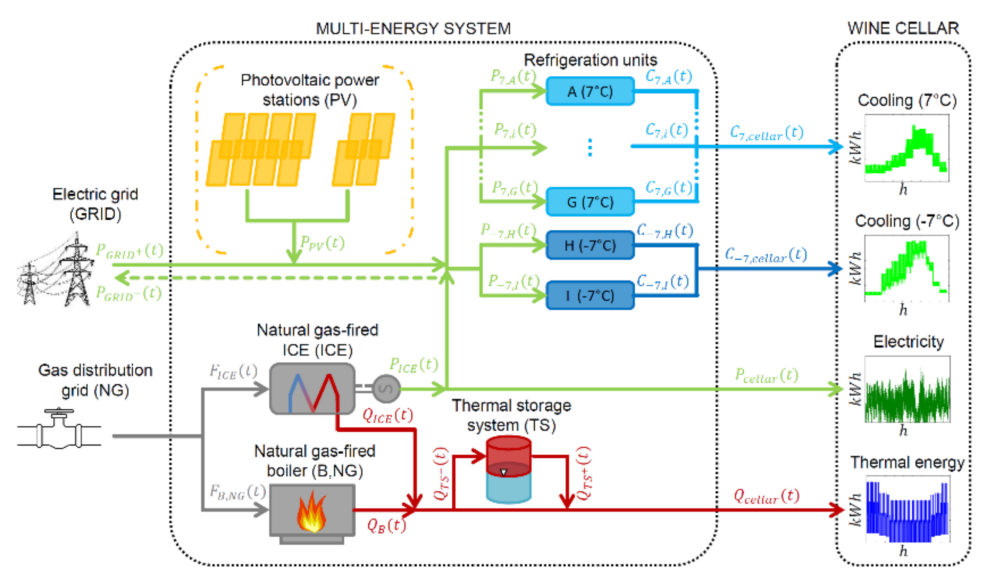

Figure 10. Alternative configuration 1: addition of an internal combustion engine (ICE) to the basic configuration in Figure 9.

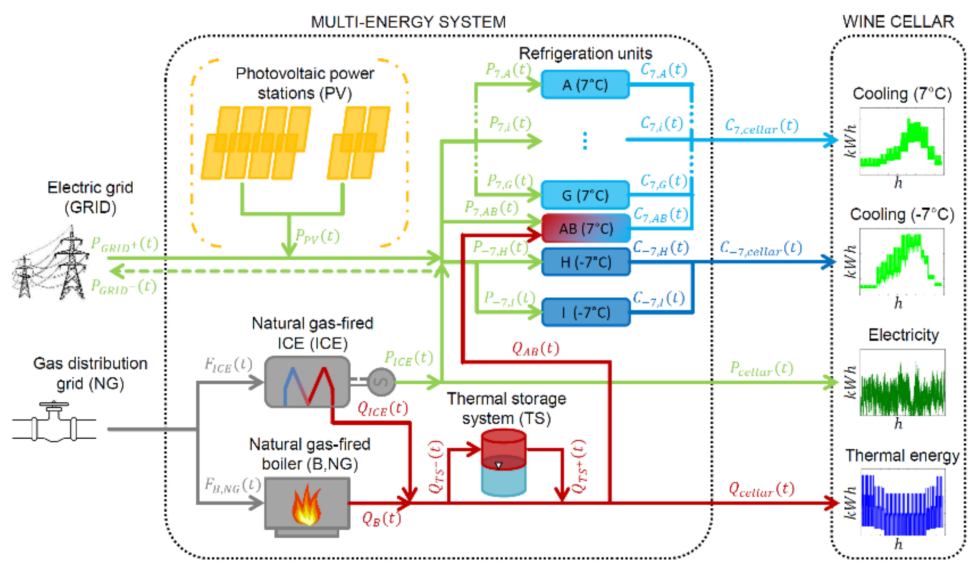

Figure 11. Alternative configuration 2: addition of an internal combustion engine (ICE) and an absorption chiller to the basic configuration in Figure 9. 


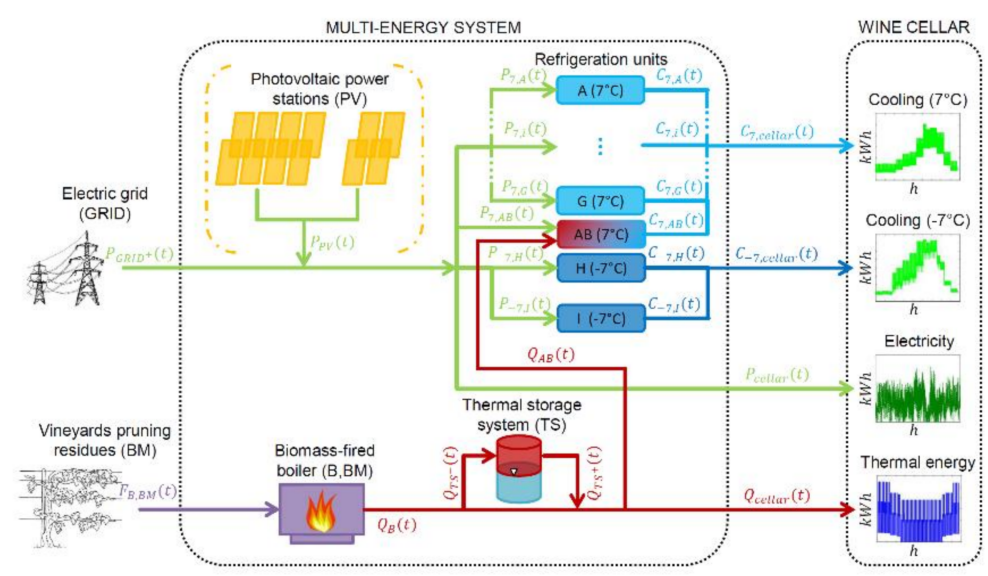

Figure 12. Alternative configuration 4: substitution of the natural gas boiler of the basic configuration in Figure 9 with a boiler fed by vineyards pruning residues, and addition of an absorption chiller.

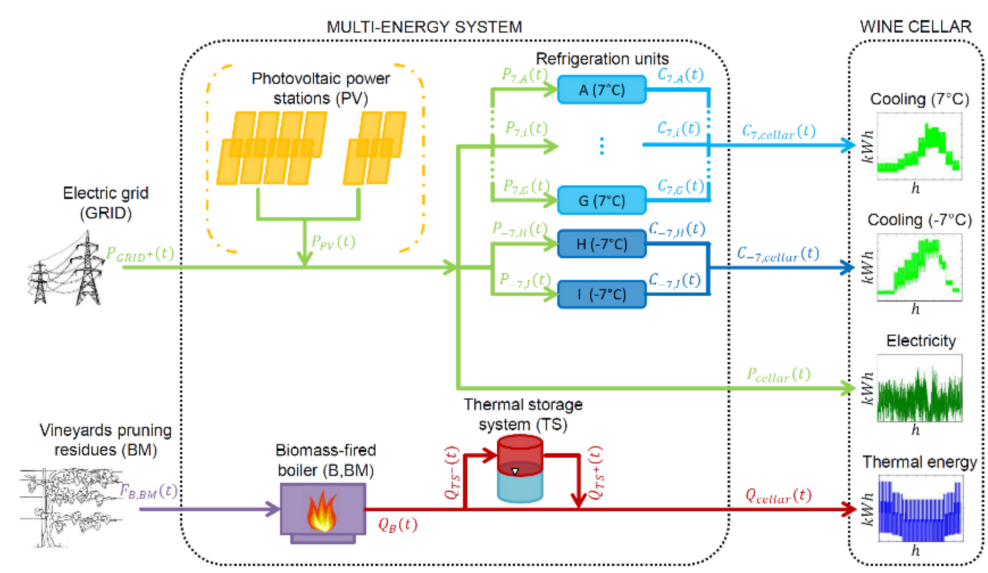

Figure 13. Alternative configuration 3: substitution of the natural gas boiler of the basic configuration in Figure 9 with a boiler fed by vineyards pruning residues.

The configurations 1 and 3 aim at replacing the present energy inputs with different ones. In the configuration 1 (Figure 10), the electricity taken from the grid is partially substituted by electricity generated by an internal combustion cogeneration engine (ICE) fueled by natural gas, which can also exploit the thermal energy available to reduce the consumption of the natural gas boiler. In the configuration 3 (Figure 13), the residues of vineyards pruning, usually left aside to generate compost, are utilized in a biomass boiler that replaces the existing natural gas one.

The configurations 2 and 4 aim at further improving the performance of the first and third ones, by exploring the potential advantages of an absorption chiller for cooling. The absorption chiller recovers part of the heat available from the ICE in the configuration 2 (Figure 11), whereas it utilizes thermal energy generated by the biomass boiler in the configuration 4 (Figure 12).

\subsection{Sizing of the New Energy Conversion Units in the Alternative Configurations}

This section discusses the choice of the size of each energy conversion unit (internal combustion engine, absorption chiller and biomass boiler) included in the four new design configurations. The general principles driving this choice consist in (i) maximizing the energy conversion with the minimum possible size (to increase profits) while covering completely the energy demands, and (ii) minimizing the environmental impact.

The size of the internal combustion engine (ICE) was chosen using the duration curves of the electricity and thermal demands of the cellar (Figure 14), and checking performance and costs of 
different types of ICE available in the market. Per each type of ICE, we calculated in a reference year the total electricity generated by the ICE, the electricity sold to and purchased from the grid, the thermal energy generated and/or dissipated. The type of ICE that guarantees the shortest period of return on investment was selected. The chosen ICE has a rated electric and thermal power of $200 \mathrm{kWe}$ and $250 \mathrm{kWt}$, respectively. This size allows an operation at nominal load (close to the maximum efficiency) for a high number of hours in a year (Figure 14a), i.e., it guarantees a good balance between investment cost and electricity purchased and sold to the grid.

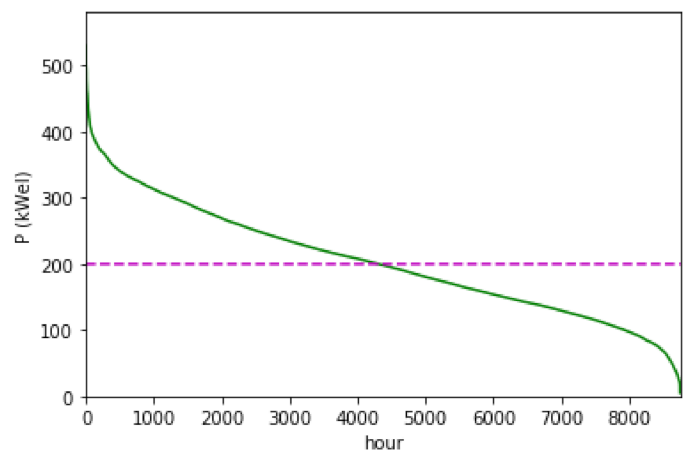

(a)

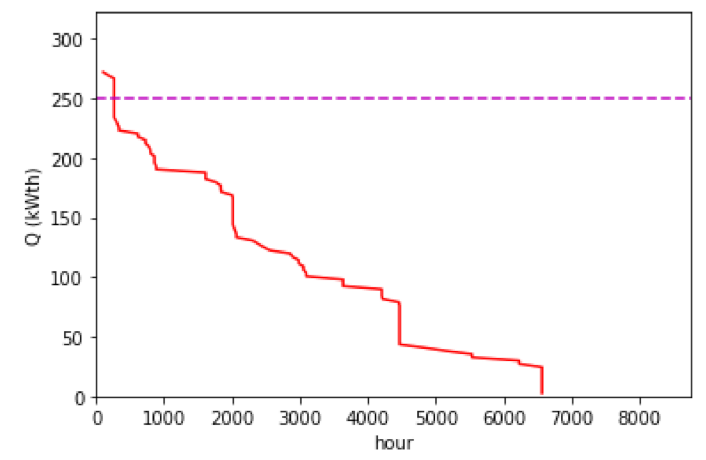

(b)

Figure 14. Duration curves for electric (a) and thermal (b) demand. Horizontal dashed lines refer to the rated powers of the $\mathrm{CHP}$ internal combustion engine.

The duration curve of the thermal energy demand (Figure 14b) shows that the thermal power recovered from the ICE at nominal operating conditions $(250 \mathrm{~kW})$ is sufficiently high to cover almost the maximum peak of thermal demand of the cellar (the peaks are covered by the thermal energy storage, since they appear for few hours during the winter days). The steep slope of the curve indicates also that there is an excess of heat available during summer that can be used to feed the absorption system of the configuration 2 (Figure 11).

The size of the absorption chiller $(\mathrm{AB})$ is strictly related to the excess of thermal energy available from the ICE. The chosen chiller has a nominal thermal power of about $250 \mathrm{~kW}$, and produces $176 \mathrm{~kW}$ of cooling power at $7{ }^{\circ} \mathrm{C}$. The chosen size provides a short period of return of investment as demonstrated in Section 5.

The biomass boiler is designed to fulfill the maximum thermal power demand of the cellar $(275 \mathrm{kWt})$. Smaller size boilers would have required a bigger thermal storage without appreciable reduction of their purchase and installation costs. The total amount of dry biomass recovered from vineyard harvesting is about 400 tons/year corresponding to $1680 \mathrm{MWh} /$ year (considering an average lower heating value of $4.2 \mathrm{kWh} / \mathrm{kg}$ for $15 \%$ of moisture content).

\subsection{Costs of the New Energy Conversion Units in the Alternative Configurations}

A precise cost evaluation of the new energy conversion units is necessary for a fair economic comparison of the proposed alternative configurations. The investment and variable costs (July 2019) of available technologies of the new conversion units are listed in Table 2 and are obtained as follows:

- Internal combustion engine (configurations 1 and 2 in Figures 10 and 11) and absorption chiller (configurations 2 and 4 in Figures 11 and 12): all data are taken from a manufacturers [27] and are in agreement with those of other manufacturers.

- Boiler and other equipment for the use of the available biomass (pruning residues, configurations 3 and 4 in Figures 12 and 13): the boiler [28] is designed to burn biomass with high content of ash, and to manage exhaust gases with high content of PM5/PM10 and carbon monoxide. The generation of heat from pruning residues requires, in addition to the boiler, a machine to 
collect and cut [29] these residues in chips (woodchipper), and a cover storage [30] to dry the obtained chips before combustion. The investment and variable costs of all equipment are shown and summed together in Table 2 to obtain the total costs of the biomass utilization chain.

Table 2. Investment and variable costs of the new energy conversion units [27-30].

\begin{tabular}{ccc}
\hline & Investment Costs $(\mathbf{k} \boldsymbol{)})$ & Variable Costs $\mathbf{( k € / \text { year } )}$ \\
\hline $\mathrm{ICE}\left(\mathrm{P}_{\mathrm{el}, \mathrm{DP}}=200 \mathrm{kWe}\right)$ & 350 & 35 \\
Wbsorption chiller $\left(\mathrm{C}_{7, \mathrm{DP}}=176 \mathrm{~kW}\right)$ & 100 & 10 \\
Woodchipper & 20 & 1 \\
Boiler and auxiliaries $\left(\mathrm{Q}_{\mathrm{DP}}=275 \mathrm{~kW}\right)$ & 90 & 1.5 \\
Storage cover & 120 & 0 \\
Total cost for biomass use & 230 & 2.5 \\
\hline
\end{tabular}

Costs related to components are shown in italics.

\section{Methods}

This section presents the approach used to optimize the performance of the energy system configurations proposed and sized in Section 3.3. The general features of the operation optimization problem are first outlined, with specific emphasis on the choice of the objective functions and on the characteristics of the equations included in the model of each conversion units. A Mixed Integer Linear Programming (MILP) approach is chosen because the performance characteristic curves of the units can be linearized without a significant loss in accuracy, as shown in $[22,25,31]$. Binary variables $(\delta$ in Equations (1)-(13)) are used to decide about activation/de-activation of each unit during operation. A flow-chart of the synthesis/design/operation approach is shown in Figure 15.

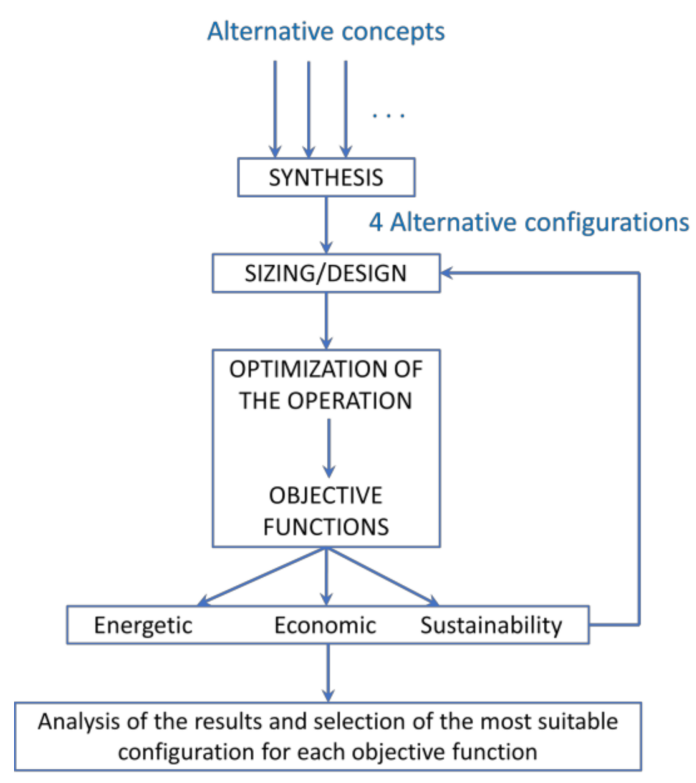

Figure 15. Flow-chart of the synthesis/design/operation optimization approach.

The MILP problem for the optimization of the operation of each configuration is set as:

Find $\mathbf{x}^{*}(t)$ and $\boldsymbol{\delta}^{*}(t)$ (i.e., the optimum values of the continuous $\mathbf{x}$, and binary, $\boldsymbol{\delta}$, decision variables associated with the operation of the energy system) that maximize or minimize the objective function $Z$ (Equation (1)) subject to the constraint relationships $\mathbf{g}(t)$ and $\mathbf{h}(t)$ (Equations (2) and (3)), which make up the model of the entire energy system of the cellar:

$$
Z=f\left(\mathbf{x}^{*}(t), \delta^{*}(t)\right)
$$




$$
\begin{aligned}
& \mathbf{g}\left(\mathbf{x}^{*}(t), \boldsymbol{\delta}^{*}(t)\right)=0 \\
& \mathbf{h}\left(\mathbf{x}^{*}(t), \boldsymbol{\delta}^{*}(t)\right) \leq 0
\end{aligned}
$$

\subsection{Model of the Energy System of the Cellar}

Among the $\mathbf{g}(t)$ and $\mathbf{h}(t)$ relationships in Equations (2) and (3), the four energy balance equations in Equations (4)-(7), one per each type of energy stream, impose that the energy demands are fulfilled during each time interval $t$ (of one hour, i.e., $\Delta t=1 \mathrm{~h}$ ). For simplicity, all balance equations are expressed in terms of power, being the length of the time intervals $(\Delta t)$ constant.

The other constraints defined by Equations (2) and (3) describe the behaviour of the thermal storage and energy conversion units, shown in Equations (8)-(17).

\subsubsection{Energy Balances}

- Electric Energy Balance (Figures 9-13)

$$
P_{\text {cellar }}(t)+P_{C_{7}}(t)+P_{C_{-7}}(t)=P_{G R I D^{+}}(t)-\left|P_{G R I D^{-}}(t)\right|+\left(P_{I C E}(t)\right)
$$

where $P_{\text {cellar }}$ is the electric power demand of all devices and services of the cellar except cooling, minus the electric power generated by the two photovoltaic solar stations $\left(P_{P V}(t)\right.$ see Section 2.2), $P_{C_{7}}$ and $P_{C_{-7}}$ are the electric power demands for cooling at 7 and $-7{ }^{\circ} \mathrm{C}$, respectively, $P_{G R I D^{+}}$and $P_{\text {GRID }}$ are the electric power taken-from/sent-to the grid, respectively, and $P_{I C E}$ is the electric power generated by the cogeneration internal combustion engine (if included).

- Thermal Energy Balance:

$$
Q_{\text {cellar }}(t)+\left(Q_{A B}(t)\right)=Q_{B}(t)+Q_{T S^{+}}(t)-Q_{T S^{-}}(t)+\left(Q_{I C E}(t)\right)
$$

where $Q_{\text {cellar }}$ is the thermal power demand of the cellar, $Q_{A B}$ is the thermal power demand of the absorption chiller (if included), $Q_{B}$ is the thermal power generated by the natural gas or biomass boiler, $Q_{T S^{+}}$and $Q_{T S^{-}}$are the thermal power discharged-from/charged-to the thermal energy storage system, respectively, and $Q_{I C E}$ is the thermal power generated by the cogeneration internal combustion engine (if included).

- $\quad$ Cooling Energy Balance $\left(7^{\circ} \mathrm{C}\right)$, which can be seen Section 3.1:

$$
C_{7, \text { cellar }}(t)=\sum_{i} C_{7, i}(t)+\left(C_{7, A B}(t)\right) \text { for } i=A, B, C, D, E, F, G \text { (see Section 3.1) }
$$

where $C_{7, \text { cellar }}$ is the cooling power demand of the cellar at $7{ }^{\circ} \mathrm{C}, C_{7, i}$ is the cooling power generated by the compression chillers of types $A$ to $G$ (Section 3.1), and $C_{7, A B}$ is the cooling power generated by the absorption chillers (if included).

- Cooling Energy Balance $\left(-7^{\circ} \mathrm{C}\right)$, with clear meaning of symbols.

$$
C_{-7, \text { cellar }}(t)=C_{-7, H}(t)+C_{-7, I}(t)
$$

\subsubsection{Operation of the Thermal Energy Storage}

The operation of the thermal storage unit (single thermocline tank) is described by the dynamic energy balance equation, which is shown in the following in terms of total volume of hot water stored at time $t[22,25,31]$ :

$$
V_{T S}(t)=V_{T S}(t-1)+\left(\frac{1}{\rho_{T S} \cdot c_{p, T S} \cdot\left(\theta_{T S, h o t}-\theta_{T S, \text { cold }}\right)}\right) \cdot\left(\eta_{T S} \cdot Q_{T S^{+}}(t)-\frac{1}{\eta_{T S}} \cdot Q_{T S^{-}}(t)\right) \cdot \Delta t
$$




$$
\begin{gathered}
0.1 \cdot V_{T S}^{M A X} \leq V_{T S}(t) \leq 0.9 \cdot V_{T S}^{M A X} \\
V_{T S}(0)=V_{T S}(n \cdot \Delta t)=V_{T S}(T)=0.1 \cdot V_{T S}^{M A X}
\end{gathered}
$$

where $\theta_{T S \text {, hot }}$ and $\theta_{T S \text {,cold }}$ are the temperatures of hot and cold water stored in the tank (they are considered constant and equal to $110^{\circ} \mathrm{C}$ and $70^{\circ} \mathrm{C}$, respectively), $\rho_{T S}$ and $c_{p, T S}$ are the density and specific heat of water at the average temperature between $\theta_{T S, h o t}$ and $\theta_{T S, \text { cold }}, \eta_{T S}$ is the charging/discharging efficiency of the storage unit, which takes into account the thermal energy losses through the tank insulated walls, $V_{T S}^{M A X}=10 \mathrm{~m}^{3}$ is the maximum capacity of the storage unit ( 0.1 and 0.9 are safety coefficients to maintain the thermal stratification within the tank), and $n$ is number of days in the optimization period $(T)$.

Equation (10) imposes that the tank is empty at the beginning and end of the optimization period $(T)$. This guarantees that the thermal energy generated by the energy conversion units during $T$ is equal to the sum of the energy required by the users plus the losses of the storage units, i.e., there is no "free" energy taken from the storage units.

\subsubsection{Operation of Energy Conversion Units}

The operation of each energy conversion unit $i$ is modelled by its characteristic curve. In general, the characteristic curve of an energy conversion unit takes the following steady-state form $[22,25,31]$ :

$$
\begin{gathered}
\varphi_{\text {in }, i}(t)=K 1_{i} \cdot \varphi_{\text {out }, i}(t)+K 2_{i} \cdot \delta_{i}(t) \\
\varphi_{\text {out }, i}(t) \leq \varphi_{\text {out }, i}^{M A X} \cdot \delta_{i}(t) \\
\varphi_{\text {out }, i}(t) \geq \varphi_{\text {out }, i}^{M I N} \cdot \delta_{i}(t)
\end{gathered}
$$

where $\varphi_{\text {in, } i}(t)$ is the energy flow (power) associated with the main input to a unit (fuel), $\varphi_{\text {out }, i}(t)$ is the energy flow (power) associated with the main ouptut of the unit (product), $\varphi_{\text {out }, i}^{M A X}$ and $\varphi_{\text {out }, i}^{M I N}$ are the maximum and minimum loads of the unit, respectively, $K 1_{i}$ and $K 2_{i}$ are (usually positive) parameters depending on the type and features of the energy conversion unit, and $\delta_{i}(t)$ is a binary variable that identifies the on/off status of the unit. When $\delta_{i}(t)=0$, Equations (12) and (13) give $\varphi_{i, \text { out }}(t)=0$ and so Equation (11) gives $\varphi_{i, i n}(t)=0$, i.e., the unit is off. When $\delta_{i}(t)=1$, Equations (12) and (13) let $\varphi_{i, o u t}(t)$ vary within the range of possible loads and the fuel consumption is calculated by Equation (11), i.e., the unit is on.

The characteristic curve equations of all energy conversion units and the associated values of the parameters $\varphi_{\text {out }, i}^{M A X}, \varphi_{\text {out }, i}^{M I N}, K 1_{i}$ and $K 2_{i}$ are shown in the following subsections.

Natural Gas-Fired and Biomass-Fired Boilers

The characteristic curves of the natural $(i=N G)$ gas and biomass fired boiler $(i=B M$, Figures 12 and 13) take the form:

$$
F_{B, i}(t)=K 1_{i} \cdot Q_{B}(t)+K 2_{i} \cdot \delta_{B, i}(t) Q_{B}(t) \leq Q_{B, i}^{M A X} \cdot \delta_{i}(t) Q_{B}(t) \geq Q_{B, i}^{M I N} \cdot \delta_{i}(t)
$$

The values of the constant parameters in Equation (14) are taken from manufacturers' data, and shown in Table 3.

Table 3. Values of the constant parameters included in the characteristic curves of the boilers.

\begin{tabular}{ccccc}
\hline Unit Type (i) & $\boldsymbol{K} 1_{i}(-)$ & $\boldsymbol{K} 2_{i}(\mathbf{k W})$ & $Q_{B, i}^{M I N}(\mathbf{k W})$ & $Q_{B, i}^{M A X}(\mathbf{k W})$ \\
\hline NG & 1.0571 & 8.0563 & 68 & 275 \\
BM & 1.0893 & 6.5359 & 75 & 300 \\
\hline
\end{tabular}




\section{Compression Chillers}

The characteristics curves of the compression chillers/heat pumps are:

$$
P_{j, i}(t)=K 1_{i} \cdot C_{j, i}(t)+K 2_{i} \cdot \delta_{i}(t) C_{j, i}(t) \leq C_{j, i}^{M A X} \cdot \delta_{i}(t) C_{j, i}(t) \geq C_{j, i}^{M I N} \cdot \delta_{i}(t)
$$

where $j=7$ and $i=A, \ldots, G$ for the units generating cooling power at $7{ }^{\circ} \mathrm{C}$, and $j=-7$ and $i=H, I$ for the units generating cooling power at $-7^{\circ} \mathrm{C}$. The values of the constant parameters in Equation (15) are obtained from manufacturers' data and shown in Table 4.

Table 4. Values of the constant parameters included in the characteristic curves of the compression chillers/heat pumps.

\begin{tabular}{ccccc}
\hline $\begin{array}{c}\text { Unit Type } \\
(\mathbf{i}) / \text { Cooling T }(\boldsymbol{j})\end{array}$ & $\boldsymbol{K} 1_{\boldsymbol{i}}(-)$ & $\boldsymbol{K} 2_{\boldsymbol{i}} \mathbf{( k W )}$ & $\boldsymbol{C}_{j, \boldsymbol{i}}^{M I N} \mathbf{( k W )}$ & $\boldsymbol{C}_{j, i}^{M A X}(\mathbf{k W})$ \\
\hline $\mathrm{A} / 7^{\circ} \mathrm{C}$ & 0.4256 & -22.165 & 73.25 & 293 \\
$\mathrm{~B} / 7^{\circ} \mathrm{C}$ & 0.4256 & -22.165 & 73.25 & 293 \\
$\mathrm{C} / 7^{\circ} \mathrm{C}$ & 0.3523 & -0.7902 & 10 & 25 \\
$\mathrm{D} / 7^{\circ} \mathrm{C}$ & 0.3523 & -0.7902 & 10 & 25 \\
$\mathrm{E} / 7^{\circ} \mathrm{C}$ & 0.3523 & -0.7902 & 10 & 25 \\
$\mathrm{~F} / 7^{\circ} \mathrm{C}$ & 0.3813 & -9.0554 & 42.5 & 170 \\
$\mathrm{G} / 7^{\circ} \mathrm{C}$ & 0.1580 & 0.0000 & 25 & 100 \\
$\mathrm{H} /-7^{\circ} \mathrm{C}$ & 0.4479 & -22.025 & 70 & 277 \\
$\mathrm{I} /-7^{\circ} \mathrm{C}$ & 0.4479 & -22.025 & 70 & 277 \\
\hline
\end{tabular}

\section{Absorption Chillers}

The absorption chiller requires both thermal and electric power inputs, so two characteristic curves (first two equations in Equation (16)) are used to describe the behavior of this unit, as suggested in [17]:

$$
Q_{A B}(t)=K 1_{A B} \cdot C_{7, A B}(t)+K 2_{A B} \cdot \delta_{A B}(t) P_{7, A B}(t)=K 3_{A B} \cdot C_{7, A B}(t)+K 4_{A B} \cdot \delta_{A B}(t) C_{7, A B}(t) \leq C_{7, A B}^{M A X} \cdot \delta_{A B}(t) C_{7, A B}(t) \geq C_{7, A B}^{M I N} \cdot \delta_{A B}(t)
$$

where the values of the constant parameters (Table 5) derive from manufacturer's data.

Table 5. Values of the constant parameters included in the characteristic curves of the absorption chiller.

\begin{tabular}{ccccccc}
\hline $\begin{array}{c}\text { Unit Type } \\
(i) / \text { Cooling T (j) }\end{array}$ & $K 1_{A B}(-)$ & $K 2_{A B}(\mathbf{k W})$ & $K 3_{A B}(-)$ & $K 4_{A B}(\mathbf{k W})$ & $C_{7, A B}^{M I N}(\mathbf{k W})$ & $C_{7, A B}^{M A X}(\mathbf{k W})$ \\
\hline $\mathrm{AB} / 7^{\circ} \mathrm{C}$ & 1.4286 & 0.0000 & 0.0032 & 0.0000 & 88 & 176 \\
\hline
\end{tabular}

Internal Combustion Cogeneration Engine

Like the absorption chiller, the behavior of the cogeneration internal combustion engine (ICE) is described with two characteristic curves (first two relationships in Equation (17)) [22,25,31]:

$$
F_{I C E}(t)=K 1_{I C E} \cdot P_{I C E}(t)+K 2_{I C E} \cdot \delta_{I C E}(t) Q_{I C E}(t) \leq K 3_{I C E} \cdot P_{I C E}(t)+K 4_{I C E} \cdot \delta_{I C E}(t) P_{I C E}(t) \leq P_{I C E}^{M A X} \cdot \delta_{I C E}(t) P_{I C E}(t) \geq P_{I C E}^{M I N} \cdot \delta_{I C E}(t)
$$

In this case, the heat recovery system of the ICE can be by-passed, so the characteristic curve linking the thermal and power production of the ICE (second relationship in Equation (17)) includes a " $\leq$ " sign. Accordingly, the thermal power $Q_{I C E}$ recovered from the ICE (cooling water, lubricating oil and exhaust gases) can vary between zero and a maximum value depending on the ICE load (PICE).

The values of the constant parameters (Table 6) are obtained from manufacturers data using the detailed ICE model presented in [31]. 
Table 6. Values of the constant parameters included in the characteristic curves of the ICE.

\begin{tabular}{ccccccc}
\hline Unit Type $(i)$ & $K_{\text {ICE }}(-)$ & $K_{\text {ICE }}(\mathbf{k W})$ & $K_{\text {ICE }}(-)$ & $K_{\text {ICE }}(\mathbf{k W})$ & $\boldsymbol{P}_{\text {ICE }}^{M I N}(\mathbf{k W})$ & $\boldsymbol{P}_{\text {ICE }}^{M A X}(\mathbf{k W})$ \\
\hline ICE & 2.2678 & 46.443 & 0.9356 & 45.679 & 100 & 200 \\
\hline
\end{tabular}

\subsection{Objective Functions}

Different objective functions are introduced in the literature to optimize the design and operation of energy conversion systems, which usually consider economic, energetic and sustainability aspects. These aspects are taken into account here considering in the optimization problem three different objective functions (Equations (18)-(20)).

For any objective function, we assume that all the four system configurations in Figures 10-13 have the primary duty to fulfil the electricity, thermal and cooling demands of the cellar. When dictated by the chosen objective function, they can generate additional electricity (that is sold to the grid), or additional heat that can be dissipated.

\subsubsection{Maximization of Profit}

The economic objective function in Equation (18) is the system gross profit (in (€)), i.e., the difference between revenues deriving from selling possible excess of electricity and operation plus maintenance costs. This objective function is to be maximized for each of the four new design configurations of the energy system of the cellar to search for the most convenient one. The optimization results allow calculating and comparing typical economic parameters, like "Payback Time" or "Net Present Value" (see Section 5):

$$
\begin{aligned}
& Z_{\text {economic }}=f_{\text {economic }}(\mathbf{x}(t), \boldsymbol{\delta}(t))= \\
& =\sum_{t=1}^{T}\left[P_{G R I D^{-}}(t) \cdot c_{E E^{-}}\right] \cdot \Delta t-\sum_{t=1}^{T}\left[P_{G R I D^{+}}(t) \cdot c_{E E^{+}}+\left(F_{B, N G}(t)+F_{I C E}(t)\right) \cdot c_{N G}+F_{B, B M}(t) \cdot c_{B M}\right] \cdot \Delta t
\end{aligned}
$$

where $c_{E E^{-}}$and $c_{E E^{+}}$are the price/cost of the electricity sold to/purchased from the national grid, $c_{N G}$ is the cost of the natural gas and $c_{B M}$ is the cost deriving from the collection and processing of the vineyards pruning residues. All these prices and costs (Table 7) are expressed per unit of energy associated with the corresponding streams $\left(\frac{€}{\mathrm{kWh}}\right)$.

Table 7. Cost of energy sources $\left(\frac{€}{\mathrm{kWh}}\right)$.

\begin{tabular}{ccccc}
\hline & $c_{E E^{-}}$ & $c_{E E^{+}}$ & $c_{N G}$ & $c_{B M}$ \\
\hline Energy cost & 0.09 & 0.144 & 0.03107 & 0.01635 \\
\hline
\end{tabular}

\subsubsection{Minimization of Primary Energy Consumption}

The "energetic" objective function (Equation (19)) is the total primary energy consumption (excluding the Sun) (in (kWh)) to supply the electricity, thermal and cooling demands of the cellar. This function is minimized to compare the operating behaviour of different configurations in terms of "fuel saving". To this end, all input streams to the energy system (electricity from the grid and fuels) are multiplied by proper coefficients $e_{i}^{\prime}\left(\frac{\mathrm{kWh} \text { primary energy }}{\mathrm{kWh} \text { input stream }}\right)$ to convert them into streams of primary energy:

$$
\begin{aligned}
& Z_{\text {energetic }}=f_{\text {energetic }}(\mathbf{x}(t), \boldsymbol{\delta}(t))= \\
& =\sum_{t=1}^{T}\left[\left(P_{G R I D^{+}}(t)+P_{G R I D^{+}}(t)\right) \cdot e_{G R I D}^{\prime}+\left(F_{B, N G}(t)+F_{I C E}(t)\right) \cdot e_{N G}^{\prime}+F_{B, B M}(t) \cdot e_{B M}^{\prime}\right] \cdot \Delta t
\end{aligned}
$$

The coefficients $e_{i}^{\prime}$ are obtained in accordance with the directives of the Italian energy service provider (GSE) [32], in particular: 
- To convert the electricity taken to the grid into primary energy an average efficiency of $41.3 \%$ is considered for the whole Italian electric system. Accordingly, $e_{G R I D}^{\prime}=\frac{1}{0.41}=2.42$;

- The primary energy spent for natural gas extraction, compression and distribution is the $5 \%$ of the energy associated with the lower heating value of natural gas. So, $e_{N G}^{\prime}=1.05$;

- The average consumption to make biomass available for energy conversion is of the order of $20 \%$, i.e., $e_{B M}^{\prime}=1,2$.

\subsubsection{Minimization of Primary Energy Consumption from Fossil Fuels}

The "sustainability" objective function (Equation (20)) calculates the whole primary energy consumption deriving from fossil fuels only (in $(\mathrm{kWh})$ ). Minimizing this objective function for all the system configurations allow creating a "sustainability ranking", which is meant as "higher degree of renewable energy source utilization". This simplified approach does not consider the expenses of fossil/renewable energy involved in the construction of the systems. Similarly to Equation (19), the primary energy consumption of fossil fuels that was necessary to generate the input streams (electricity from the grid and fuels) are calculated in Equation (20) using the coefficients $e_{i}^{\prime \prime}\left(\frac{\mathrm{kWh}_{\text {fossil fuel }}}{\mathrm{kWh} \text { input stream }}\right)$.

$$
\begin{aligned}
& Z_{\text {sustainability }}=f_{\text {sustainability }}(\mathbf{x}(t), \boldsymbol{\delta}(t))= \\
& =\sum_{t=1}^{T}\left[\left(P_{G R I D^{+}}(t)+P_{G R I D^{+}}(t)\right) \cdot e_{G R I D}^{\prime \prime}+\left(F_{B, N G}(t)+F_{I C E}(t)\right) \cdot e_{N G}^{\prime \prime}+F_{B, B M}(t) \cdot e_{B M}^{\prime \prime}\right] \cdot \Delta t
\end{aligned}
$$

Again, the coefficients $e_{i}^{\prime \prime}$ are obtained in accordance with the directives of the Italian energy service provider (GSE) [32]:

- The average share of electricity production from renewables in the Italian electric systems is $19.4 \%$, so $e_{G R I D}^{\prime \prime}=e_{G R I D}^{\prime} \cdot(1-0.194)=2.42 \cdot 0.806=1.95$;

- Natural gas is a fossil fuel, so $e_{N G}^{\prime}=e_{N G}^{\prime \prime}=1.05$;

- The harvesting, transport and processing of biomass (vineyards pruning residues) spend an amount of fossil primary energy (mainly oil for tractors) equal to the $20 \%$ of the total energy available from biomass [32], i.e., $e_{B M}^{\prime \prime}=e_{B M}^{\prime} \cdot(1-0.80)=1.20 \cdot 0.2=0.24$.

\section{Results}

A total number of twelve optimization runs were carried out to find the best operation of the four alternative configuration presented in Section 3 (Figures 10-13) according with the three objective functions defined in Section 4.2 (Equations (18)-(20)). The resulting optimal operation are first discussed (Section 5.1) considering, for brevity, only the best performing configurations (configurations 2 and 4 in Section 3.2). Finally, a sensitivity analysis is presented to evaluate the influence of the price/cost of the electricity and natural gas on (i) the optimum operation of the cellar energy systems and (ii) the economic convenience of increasing the share of renewable energy utilization by using the pruning residues as fuel.

\subsection{Optimum Operation of the Best Performing Configurations}

Typical winter and summer days (in Figures 16 and 17) are chosen to show the daily behavior of each configuration, because of the higher energy demands in these seasons (Section 2.2). On the contrary, during the middle seasons there are no peaks of demand (neither high nor low) and therefore the matching between production and demand is more straightforward (and less meaningful). 

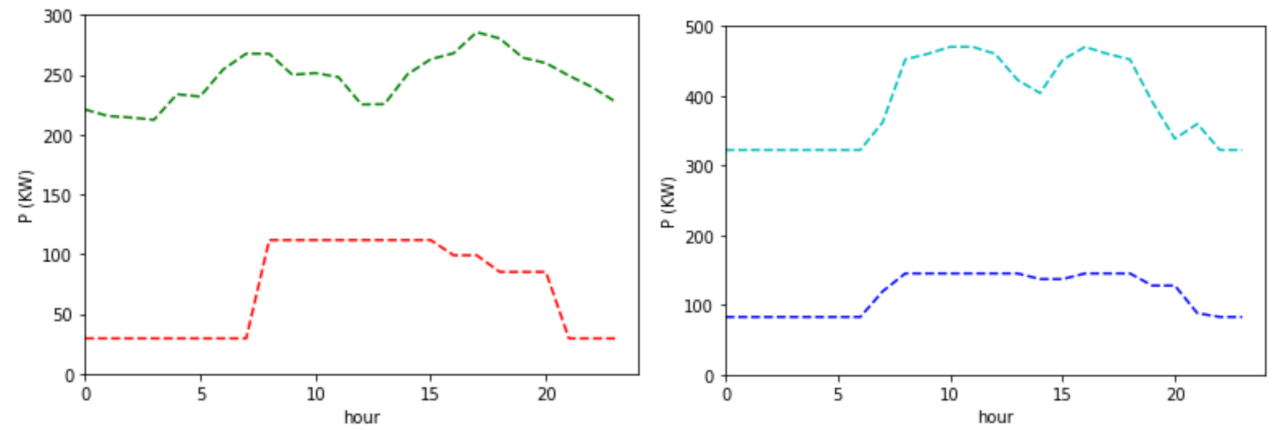

Figure 16. Energy demands in a typical summer day: electricity (green), heat (red), cooling at $7{ }^{\circ} \mathrm{C}$ (light blue), cooling at $-7^{\circ} \mathrm{C}$ (blue).
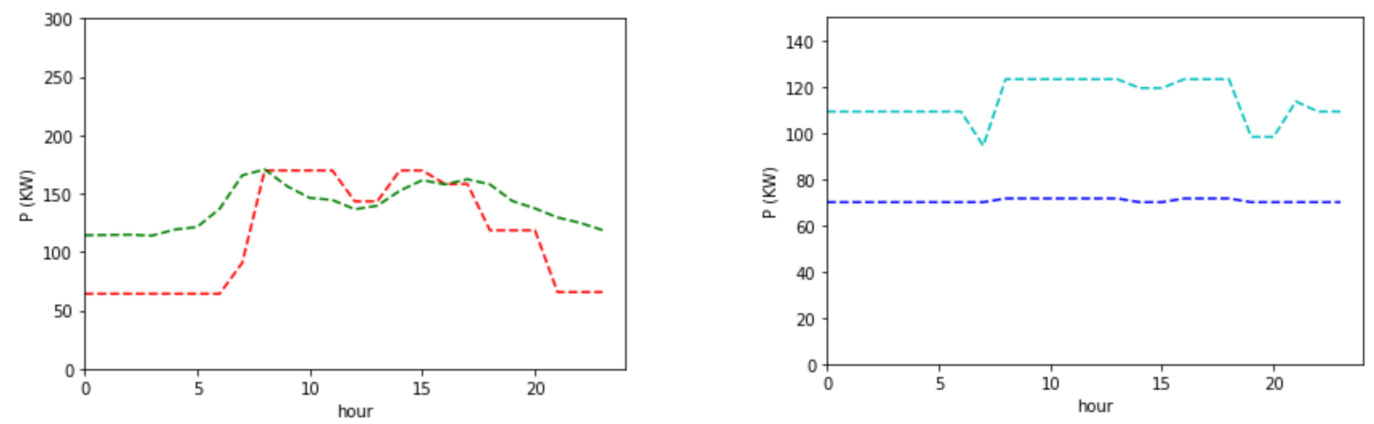

Figure 17. Energy demands in typical winter day: electricity (green), heat (red), cooling at $7{ }^{\circ} \mathrm{C}$ (light blue), cooling at $-7^{\circ} \mathrm{C}$ (blue).

\subsubsection{Alternative Configuration 2: Addition of A Natural Gas ICE and An Absorption Chiller}

The addition of a cogeneration system based on an CHP internal combustion engine fueled by natural gas and an absorption chiller (Figure 11) aims at reducing the energy cost and the primary energy consumption of the cellar. This is because the absorption chillers reduce the demand of electricity taken from the grid for cooling whereas the ICE increases the electricity sold to the grid. On the other hand, the thermal demand of the cellar increases because of the requirement of the absorption chiller, but this demand is totally supplied by the heat recovered from the ICE. The lower electric to thermal ratio is also favorable from the economic point of view, as shown below.

Figures 18-20 show the optimal operation of the energy system during two typical days, representing the winter and summer seasons (Figures 16 and 17). The maximization of profit suggests operating the ICE at constant maximum load both in winter and summer time (blue lines in Figure 18a,b). 
(a)

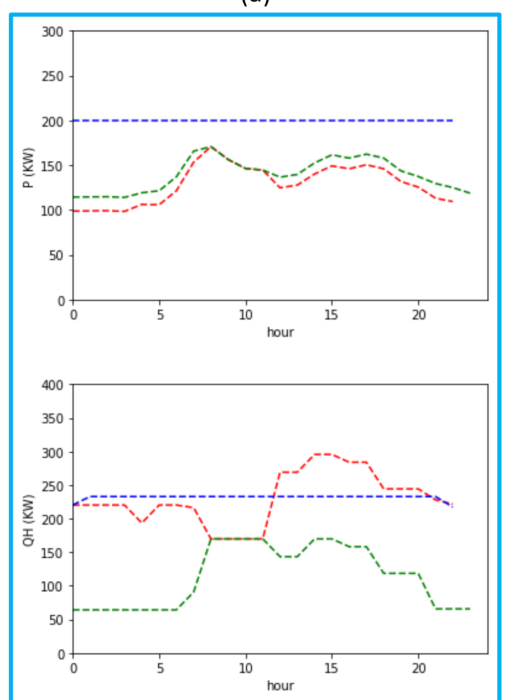

(b)

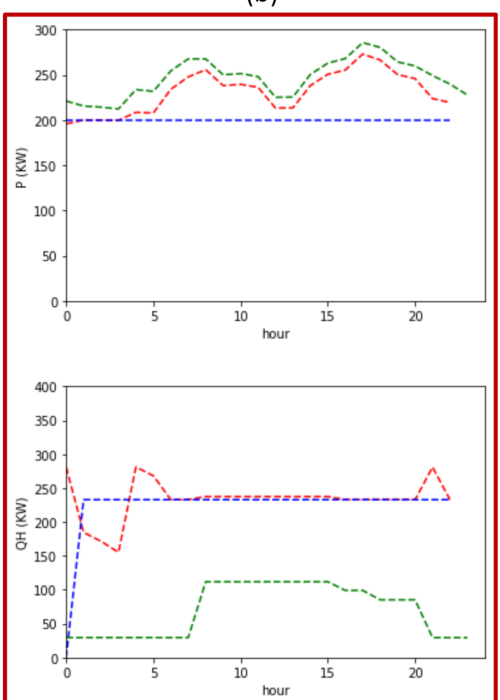

Figure 18. Maximization of profit for the system configuration in Figure 11 (addition of ICE and absorption chiller): optimum electric $(\mathrm{P})$ and thermal power production $(\mathrm{QH})$ in winter $(\mathbf{a})$ and in summer (b) by the ICE (blue lines). Green and red lines show the changes in electric (P) and thermal $(\mathrm{QH})$ demands due to the addition of the absorber chiller (green lines-before addition, red lines-after addition).

(a)

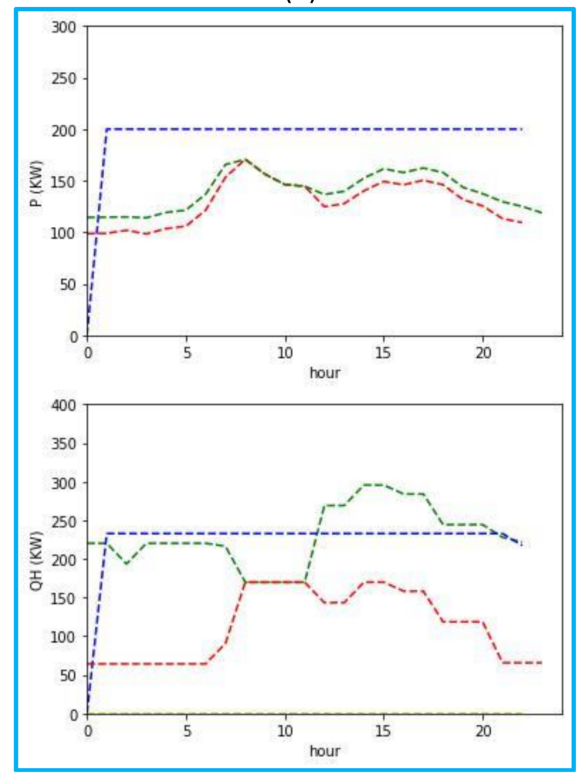

(b)

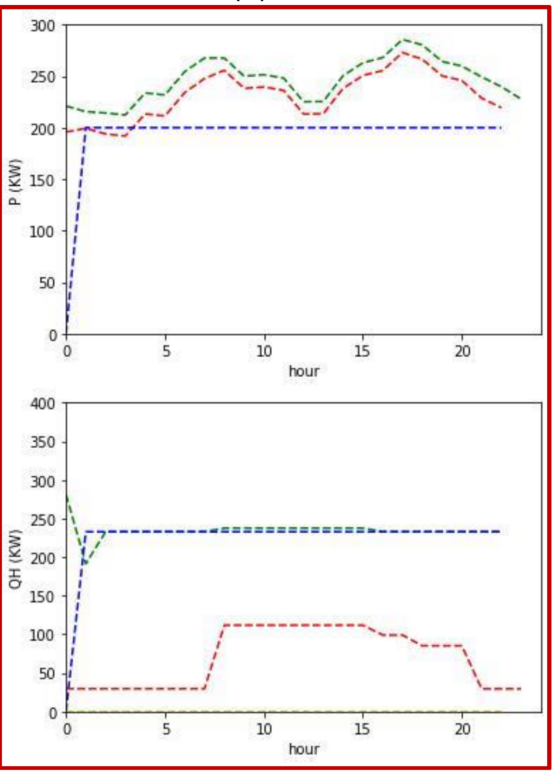

Figure 19. Minimization of primary energy consumption for the system configuration in Figure 11 (addition of ICE and absorption chiller): optimum electric $(\mathrm{P})$ and thermal power production $(\mathrm{QH})$ in winter (a) and in summer (b) by the ICE (blue lines). Green and red lines show the changes in electric $(\mathrm{P})$ and thermal $(\mathrm{QH})$ demands due to the addition of the absorber chiller (green lines-before addition, red lines-after addition). 
(a)

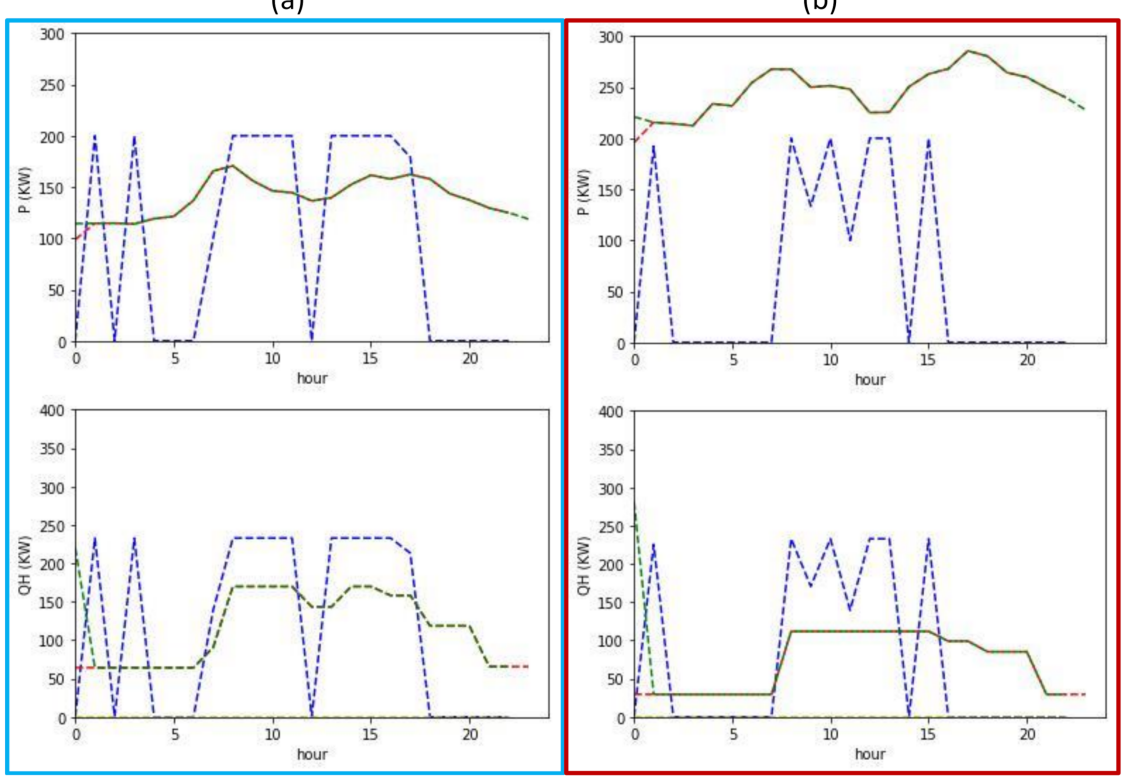

Figure 20. Minimization of primary energy consumption from fossil fuels for the system configuration in Figure 11 (addition of ICE and absorption chiller): optimum electric $(\mathrm{P})$ and thermal power production $(\mathrm{QH})$ in winter (a) and in summer (b) by the ICE (blue lines). Green and red lines show the changes in electric $(\mathrm{P})$ and thermal $(\mathrm{QH})$ demands due to the addition of the absorber chiller (green lines-before addition, red lines-after addition).

In these periods, the heat generated by the engine is sufficient to cover completely the thermal energy required by the cellar. Excess heat is used by the absorber for cooling. As clearly from comparing Figures 18 and 19, the minimization of primary energy consumption (Figure 18) requires an operation of ICE very similar to that of maximum profit (Figure 19) both in winter and in summer.

Unlike the previous objectives, the minimization of primary energy consumption from fossil fuels (Figure 20) does not suggest generating cooling using the thermal energy recovered from the ICE in the absorption system.

The graphs in Figure 20a,b show that, to minimize the fossil fuel consumption, the ICE works only to supply the heat demand of the cellar, because it is more convenient than using the natural gas boiler. Any increase in the ICE load compared to that necessary to fulfil strictly the heat demand would increase the natural gas consumption, and therefore is not suggested by this "sustainability" criterion. Thus, the absorption chiller does not work, so that the thermal energy requirements remain the same as those of the reference system in Figure 9.

5.1.2. Alternative Configuration 4: Substitution of the Existing Natural Gas Boiler with A Boiler Fed by Vineyards Pruning Residues and Addition of An Absorption Chiller

The substitution of the natural gas boiler in the basic configuration with a biomass boiler and the addition of an absorption chiller (Figure 12) is the best configuration to reduce the primary energy consumption from fossil fuels (i.e., to increase the share of renewable energy utilization).

As appears from Figure 21, the results of profit maximization indicate that the operation of the absorption chiller is not convenient during wintertime (Figure 21a), whereas it is advantageous during summer when the heat is used to generate cooling energy (Figure 21b), so reducing the demand of electricity in the compression chillers. 
(a)

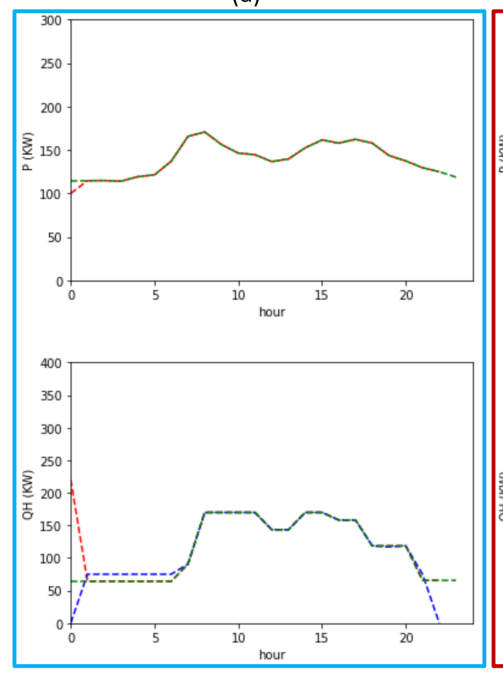

(b)

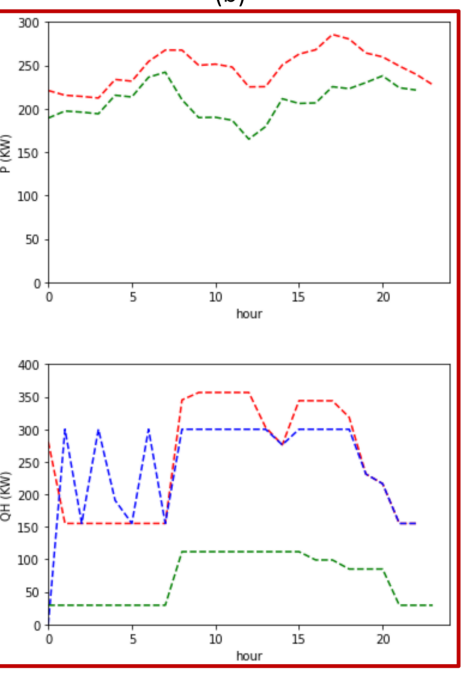

Figure 21. Maximization of profit for the system configuration in Figure 12 (substitution of the natural gas boiler with a biomass boiler and addition of an absorption chiller): optimum thermal power production of the biomass boiler $(\mathrm{QH})$ in winter $(\mathbf{a})$ and in summer $(\mathbf{b})$ by the ICE (blue lines). Green and red lines show the changes in electric $(\mathrm{P})$ and thermal $(\mathrm{QH})$ demands due to the addition of the absorber chiller (green lines—before addition, red lines—after addition).

The minimization of the primary energy consumption (Figure 22) asks the biomass boiler to supply only the thermal demand of the cellar, i.e., the absorption chiller does not work. The grid supplies the necessary electricity, as occurs in the basic configuration (Figure 9). The minimization of the primary energy consumption from fossil fuels suggests using the absorber only during the summer (Figure 23), so reducing the electricity demand from the grid (mostly generated by fossil fuels) with respect to the basic configuration.

(a)

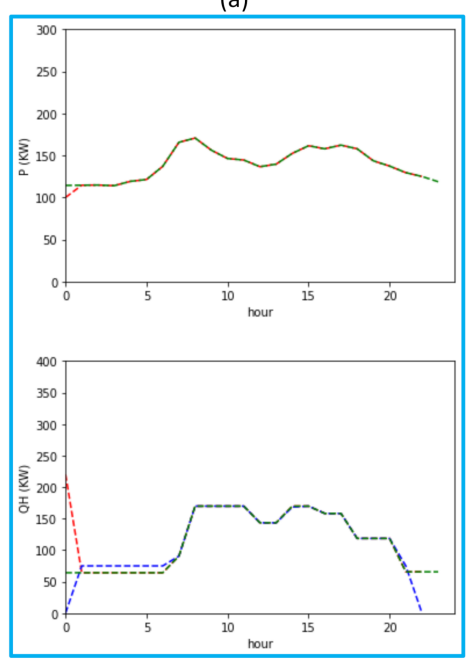

(b)

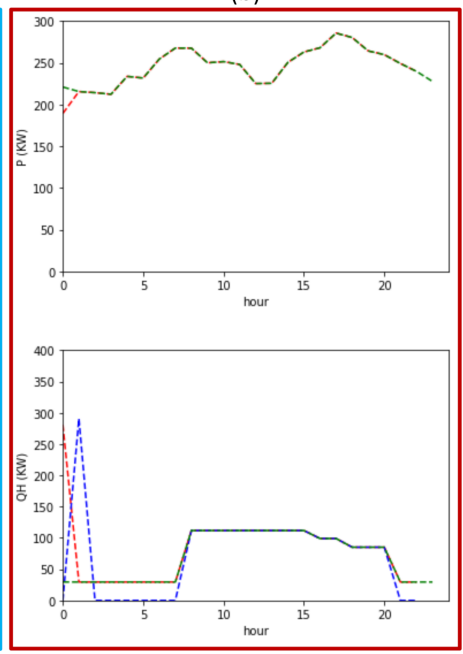

Figure 22. Minimization of primary energy consumption for the system configuration in Figure 12 (substitution of the natural gas boiler with a biomass boiler and addition of an absorption chiller): optimum thermal power production of the biomass boiler $(\mathrm{QH})$ in winter $(\mathbf{a})$ and in summer $(\mathbf{b})$ by the ICE (blue lines). Green and red lines show the changes in electric $(\mathrm{P})$ and thermal $(\mathrm{QH})$ demands due to the addition of the absorber chiller (green lines—before addition, red lines-after addition). 
(a)

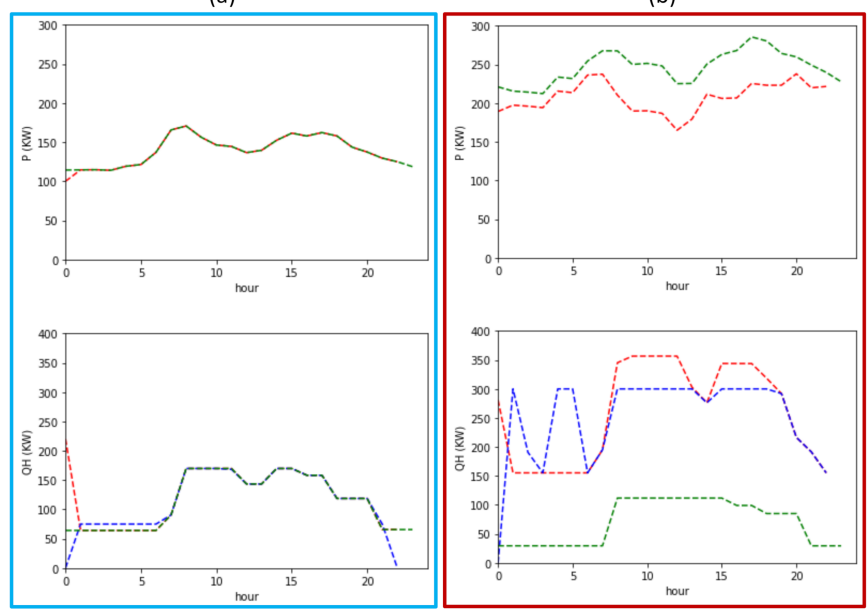

Figure 23. Minimization of primary energy consumption from fossil fuels for the system configuration in Figure 12 (substitution of the natural gas boiler with a biomass boiler and addition of an absorption chiller): optimum thermal power production of the biomass boiler $(\mathrm{QH})$ in winter (a) and in summer (b) by the ICE (blue lines). Green and red lines show the changes in electric $(\mathrm{P})$ and thermal $(\mathrm{QH})$ demands due to the addition of the absorber chiller (green lines-before addition, red lines-after addition).

\subsection{Comparison between the Yearly Optimum Performace of the Alternative Configurations}

This section compares the optimization results for one-year of operation of all alternative configurations (in Figures 10-13) according to the three objective functions (Equations (18)-(20)). Note that the economic objective function in Equation (18) includes only the operating costs deriving from the purchase of electricity and fuels $\left(C_{i}\right)$, whereas it does not include the maintenance costs, which are added after the optimization runs (since they do not affect the optimal loads of the units, but they affect the total operating cost). Accordingly, the total operation costs $\left(C_{O \& M}\right)$ are:

$$
C_{O \& M}=\sum\left(C_{i}+C_{M_{i}}\right)
$$

The configuration 2 (addition of ICE and absorption chiller, Figure 11) achieves the minimum value of operating and maintenance costs considering the criterion of profit maximization (Figure 24). The results do not change substantially keeping the same criterion and removing the absorber (i.e., considering the configuration 1, Figure 10). The configuration 2 obtains similar results also when minimizing the primary energy consumption.

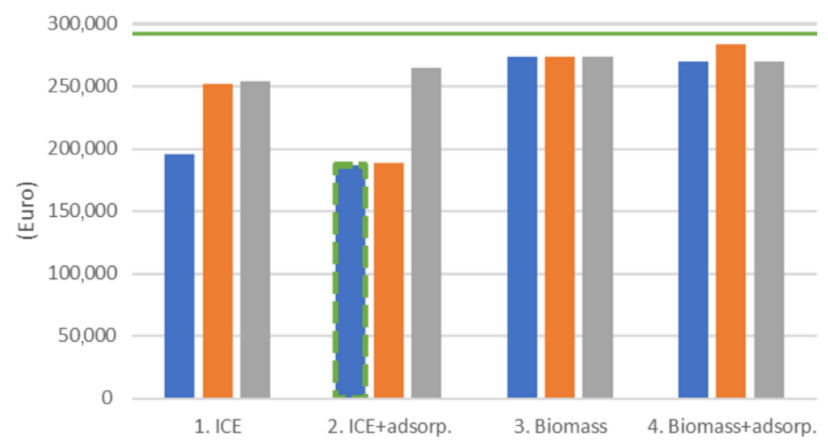

Figure 24. Operating and maintenance costs $\left(C_{O \& M}\right.$ in Equation (21)) for different configurations and objective functions. Blue, orange and grey bars refer, in the order, to maximization of profit, minimization of primary energy consumption, minimization of primary energy consumption from fossil fuels. The bar circled with green dashed line indicates the best absolute result, the green line the basic configuration results. 
The configuration 2 (Figure 11) is still the best one to reach the minimum value of primary energy consumption (Figure 25).

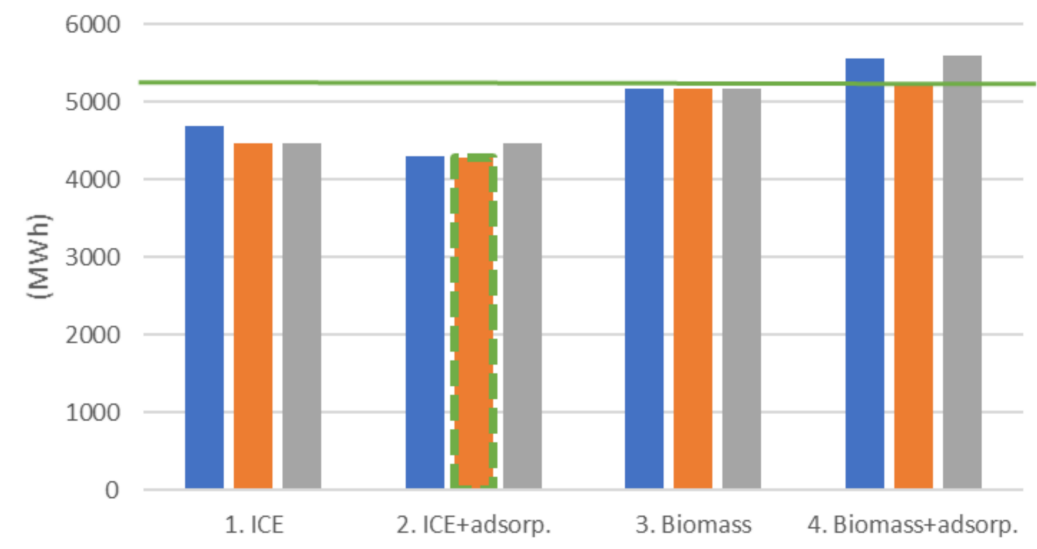

Figure 25. Primary energy consumption for different configurations.

Conversely, the best configuration to reach the minimum value of primary energy consumption from fossil fuels ("sustainability" objective function, Figure 26) is configuration 4 (Figure 12), in which the natural gas boiler is substituted by a biomass one and the absorption chiller is added. Nevertheless, comparing the results of the configurations 3 and 4 , it appears that the contribution of the absorber to the reduction of "sustainability" objective function is not fundamental.

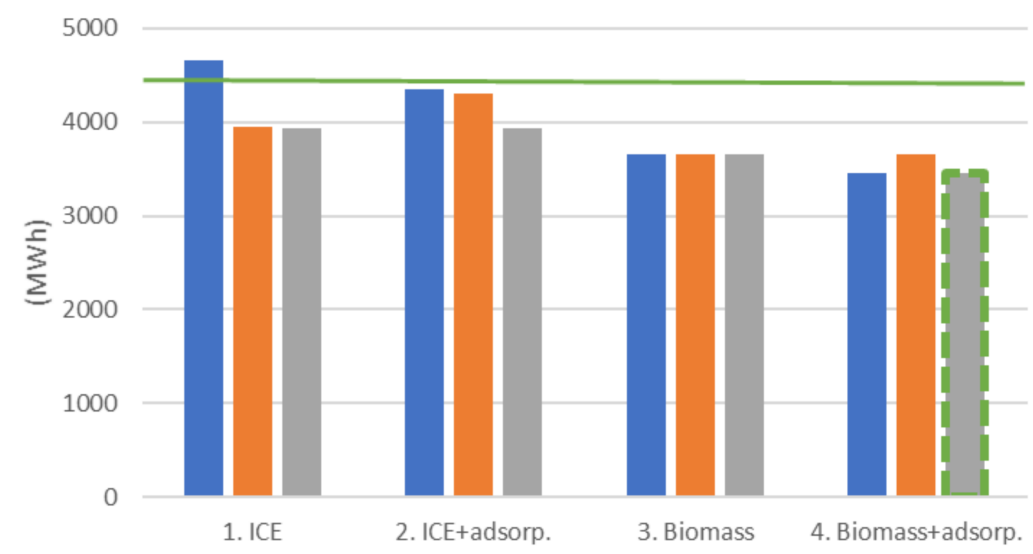

Figure 26. Primary energy consumption from fossil fuels for different configurations.

In summary:

\subsubsection{Maximization of Profit}

Cogeneration helps reduce the costs for generating energy. In fact, the best configurations in this respect are those including the $\mathrm{CHP}$ engine (configurations 1 and 2). The addition of the absorption chiller further improves the profits, but not substantially.

Table 8 shows the detailed results obtained by maximization of profits. Operation and maintenance costs (O\&M) are compared with those of the basic configuration (Figure 9) to evaluate the PayBack time and Net Present Value. 
Table 8. Economic analysis considering the operations which maximize profits.

\begin{tabular}{lccccc}
\hline & $\begin{array}{c}\text { O\&M Costs } \\
(\mathbf{\epsilon} / \text { year) }\end{array}$ & $\begin{array}{c}\text { Savings Compared } \\
\text { to Basic Conf. } \\
(\mathbf{\epsilon} / \text { year) }\end{array}$ & $\begin{array}{c}\text { Investment Cost } \\
(\mathbf{\epsilon})\end{array}$ & $\begin{array}{c}\text { PBT } \\
\text { (year) }\end{array}$ & $\begin{array}{c}\text { NPV at 25 years } \\
(\mathbf{\epsilon})\end{array}$ \\
\hline Configuration 1 & 195,360 & 93,149 & 350,000 & 4.3 & 962,832 \\
Configuration 2 & 187,046 & 101,463 & 450,000 & 5.1 & 980,009 \\
Configuration 3 & 273,683 & 14,826 & 230,000 & 30.6 & $-21,043$ \\
Configuration 4 & 269,917 & 18,592 & 330,000 & 44.8 & $-67,966$ \\
\hline
\end{tabular}

The economic savings are defined as:

$$
\text { Saving }_{i}=\left(C_{i, \text { base conf }}-C_{O \& M i}\right)
$$

where $C_{i, \text { base conf }}$ is the operation and maintenance cost of basic configuration.

PayBack Time (PBT) and Net Present Value (NPV) are calculated as:

$$
\begin{gathered}
\text { Saving }_{i} *\left(\sum_{t=1}^{P B T_{i}} \frac{1}{(1+j)^{t}}\right)=I_{0_{i}} \\
N P V_{i}=\left(\text { Saving }_{i}\right) *\left(\sum_{\mathrm{t}=1}^{n} \frac{1}{(1+\mathrm{j})^{t}}\right)-I_{0_{\mathrm{i}}}
\end{gathered}
$$

where $I_{o_{i}}=$ Investment cost, supposed entirely paid in the first year, $j=$ discount rate, fixed at $5 \%$ (typical value for investment in the energetic sector) and $n=$ number of lifetime years, fixed at 25 years.

Configuration 2 (Figure 11) implies higher total costs than configuration 1 (Figure 10) due to the higher investment and maintenance costs of the absorption chiller. However, the absorption chiller permits the thermal energy recovery from the ICE and the reduction of the electricity used by the compression chillers. In this way, the ICE shows a higher utilization factor and energy conversion efficiency over the year. The NPV at 25 years of configuration 2 (980 k€) is significantly higher than that of configurations 3 and 4 (negative NPV), whereas the advantage is lower in comparison with configuration 1 (about $963 \mathrm{k} €$ ).

The alternative configurations that utilize biomass (configurations 3 and 4 in Figures 12 and 13) show very high investment costs for the equipment required for the pruning residues use (woodchipper, cover storage and boiler, Section 3.4) and the absorption chiller that are not compensated by the obtainable savings during operation. Thus, an economic break-even point is not reached within the estimated lifespan of the equipment ( 25 years) and the associated NPV does not reach a positive value. Considering the current prices of energy and devices, and a discount rate of $5 \%$, the estimated time required to recover the cost of an investment (PBT) is higher than 30 years, which can hardly be reached by the system without a total replacement of the devices. These configurations could become competitive in case of a remarkable increase of the electricity and natural gas costs (Section 5.3). Otherwise, these configurations could be convenient only in presence of adequate incentives.

\subsubsection{Minimization of Primary Energy Consumption}

The addition of ICE and absorption chiller (configuration 2 in Figure 11) to the basic configuration (Figure 9) is the best solution to reduce the consumption of primary energy. The reduction is of about $18 \%$ (about $4284 \mathrm{MWh}$ versus $5201 \mathrm{MWh}$ ) compared to the basic configuration, which corresponds to an annual average efficiency in the conversion of the primary energy (total annual generated energy divided by total annual consumed primary energy) of $61.2 \%$ (versus $50.4 \%$ of the basic configuration).

Using the ICE only (configuration 1 in Figure 10), part of the thermal energy produced by the engine is not utilized, but has to be released to the ambient using an evaporative tower. In this case, 
the primary energy consumption is higher (about $4466 \mathrm{MWh}$ ), and the annual efficiency lower (58.7\%), than in configuration 2 because cooling is totally provided by the compression chillers.

The primary energy consumption of the configurations 3 and 4 , in which the natural gas boiler is substituted with a biomass one, is very similar to that of the basic configuration (efficiency in between 50.2 and $50.7 \%$ ) due to the separate production of thermal and electric energy.

\subsubsection{Minimization of the Primary Energy Consumption from Fossil Fuels}

Burning pruning residues in the biomass boiler reduces the dependence on fossil fuels. The use of the biomass for heating purposes only (configuration 3 in Figure 13) leads to a maximum reduction in fossil fuels consumption of $16 \%$, which requires burning about half of the available biomass (200 tons versus 400 tons harvested in a year) while the remaining half can be composted. If the thermal power generated in the biomass boiler is also utilized by the absorption chiller (configuration 4 in Figure 12), the consumption of primary energy from fossil fuels is further reduced, up to $20 \%$ lower than that of the basic configuration. This is the best configuration in terms of share of renewable energy utilization in the cellar, the maximum achievable annual share (considering the contribution of both PV and biomass) is equal to $35 \%$. In this case almost the total amount of available biomass (400 tons) is burned. In the reference cellar, it is not possible to further increase the renewables contribution considering a biomass boiler of larger size because there would not be sufficient pruning residues, as well as the installation of additional PV power is excluded because of lack of available surface area (Section 3.1).

Conversely, including the natural gas fueled ICE (configurations 1 and 2, Figures 10 and 11), either alone or combined with the absorption chiller, results in a consumption of primary energy from fossil fuels very similar to or even higher than that of the basic configuration. The resulting shares of renewable energy utilization is in between $12 \%$ (configuration 1 operated to maximize the profit) and $26 \%$ (configurations 1 and 2 operated to minimize the primary energy consumption from fossil fuels).

\subsection{Sensitivity Analysis}

A sensitivity analysis on the prices of the natural gas and electricity (purchased from and/or sold to the grid) are proposed to verify the goodness of the sizes chosen for the CHP internal combustion engine and the absorption chiller (Section 3.3) in configurations 1 and 2 (Figures 10 and 11).

The size of the engine selected here ( $200 \mathrm{kWe}$ ) guarantees a generally good behavior of the system from the energetic point of view (i.e., the dissipation of thermal energy is relatively low) and a short period of return of the investment (Table 8). Figure 27 shows the results of the optimization of the operation of configuration 2 for different costs of the natural gas and of the electricity purchased from the grid at constant price of the electricity sold to the grid.

(a)

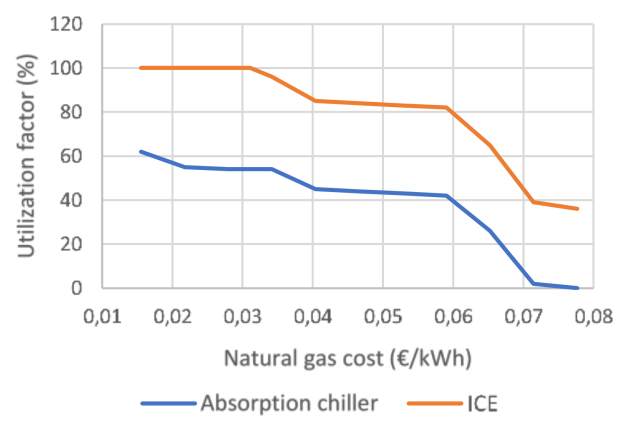

(b)

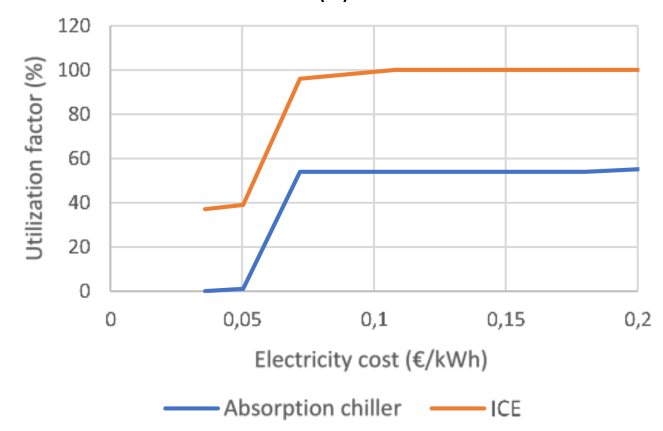

Figure 27. Internal Combustion Engine (ICE) and Absorption chiller behavior under variations of the cost of natural gas (a) and electricity $(\mathbf{b})$. 
When the cost of natural gas is below $0.04 € / \mathrm{kWh}$ (Figure 27a), it is convenient to keep the ICE at nominal load in order to sell the maximum possible amount of electricity and use the heat for the absorption chiller to generate cooling. If this cost is in between 0.04 and $0.06 € / \mathrm{kWh}$, it is convenient to use the ICE for trigeneration, without selling or purchasing electricity to/from the grid (i.e., self-consumption). In contrast, if the cost is higher than $0.06 € / \mathrm{kWh}$, it is no more convenient to generate cooling from the heat recovered from the engine using the absorption chiller. In fact, the utilization factor of the absorption chiller is reduced to zero and the ICE is used only to fulfill the other thermal requirements of the cellar.

High utilization factors of both ICE and absorption chiller are convenient also the cost of the electricity taken from the grid is above $0.07 € / \mathrm{kWh}$ (Figure $27 \mathrm{~b}$ ). Since this cost is very rarely below $0.09 € / \mathrm{kWh}$, the operation of the engine is certainly profitable. Different values of this cost may change the period of return of investment, depending on the other economic parameters.

Finally, a sensitivity analysis is performed to evaluate the increase in the natural gas price that would be necessary to make the utilization of biomass economically acceptable (i.e., when the economic savings derived from burning the zero-cost biomass compensates the associated installation costs). In fact, Section 5.2 clearly shows that a massive use of the available renewable energy sources (mainly biomass) is not convenient from an economic point of view because of the high investment costs of the biomass utilization chain (Tables 2 and 8). To this end, the economic analysis in Section 5.2.1 is performed for the two alternative configurations including the biomass boiler (configurations 3 and 4 in Figures 12 and 13) considering an increased price of the natural gas. In particular, the reference price used in the economic analysis in Table $8(0.0373 € / \mathrm{kWh})$ is increased by $25 \%, 50 \%$ and $100 \%$.

The results (Table 9) show that the increase in the price of natural gas and the consequent increase in the operating costs of the basic configuration, leads to an increase in the economic savings of both configurations and, in turn, in the NPVs at 25 years (which now result positive in all cases). Accordingly, the higher the natural gas price the lower the payback time of the investments (PBT in Table 9). A price rise of $+25 \%$, which is realistic in the short term, entails a significant reduction in PBT (down to 16 years) and an economic break-even point within the equipment lifespan. However, PBT higher than 10 years are not attractive in the industrial field, a minimum $50 \%$ increase in the price of natural gas is required to make configuration 3 economically desirable.

Table 9. Economical parameters at increased price of natural gas.

\begin{tabular}{ccccc}
\hline $\begin{array}{c}\text { Configuration } \\
\text { (Figures 12 and 13) }\end{array}$ & $\begin{array}{c}\text { Natural Gas Price } \\
(\mathbf{\epsilon} / \mathbf{k W h})\end{array}$ & $\begin{array}{c}\text { Saving Compared } \\
\text { to Basic Conf. } \\
(\boldsymbol{\epsilon} / \text { year) }\end{array}$ & PBT (year) & $\begin{array}{c}\text { NPV at 25 years } \\
(\boldsymbol{\epsilon})\end{array}$ \\
\hline 3 & $0.0466(+25 \%)$ & $\mathbf{2 2 , 6 2 4}$ & 14.6 & 88,854 \\
3 & $0.0559(+50 \%)$ & $\mathbf{3 0 , 4 1 9}$ & 9.7 & 198,726 \\
3 & $0.0746(+100 \%)$ & $\mathbf{4 6 , 0 1 0}$ & 5.9 & 418,471 \\
4 & $0.0466(+25 \%)$ & $\mathbf{2 6 , 3 8 9}$ & 20.1 & 41,932 \\
4 & $0.0559(+50 \%)$ & $\mathbf{3 4 , 1 8 5}$ & 13.5 & 151,805 \\
4 & $0.0746(+100 \%)$ & $\mathbf{4 9 , 7 7 6}$ & 8.3 & 371,549 \\
\hline
\end{tabular}

\section{Conclusions}

This paper aims at finding the best option to supply energy (electricity, heating, and cooling) to wine cellars, a topic scarcely considered in the literature in spite of the high energy intensity of these systems. To this end, a real Prosecco wine cellar in the north east of Italy is taken as reference and its whole energy systems is optimized in terms of maximum profit, efficiency and share of renewable energy utilization. The paper contents can be subdivided in three parts: 
- Analysis of the energy demands over a year of all devices/processes in the reference cellar to build reliable chronological profiles of thermal, electric, and cooling demands.

- Proposal of four alternative configurations for the generation of the electric, thermal and cooling demands of the cellar. All new devices in the alternative configurations are chosen and sized according to the real energy requirements of the cellar and a high readiness levels of the technologies (only mature and commercially available devices are considered).

- Development of reliable models of each configuration and optimization of their operation along the year to achieve the best energetic and economic performances, taking into account the degree of sustainability, measured by lower utilization of fossil fuels (i.e., higher share of renewable energy utilization).

The results clearly show that the combined production of electrical and thermal power is economically and energetically more efficient compared to the separate production. This solution is currently not considered in most of the existing cellars because of the low demand of thermal energy compared to electricity. However, the inclusion of a properly sized absorption chiller (176 kW of rated cooling power) to partially replace the existing compression chillers results in more balanced ratio between electric and thermal demands, and so allows an efficient use of a natural gas-fueled CHP internal combustion engine ( $200 \mathrm{kWe}$ of rated electric power). This configuration (configuration 2 in Figure 11) permits a reduction of both the primary energy consumption $(-18 \%)$ and the operating costs $(-35 \%)$ when operated to follow the maximum profit (considering the current energy prices). This option corresponds to an increase in annual average efficiency from $50.4 \%$ of the basic configuration to $61.2 \%$. At constant electricity price, the use of the CHP engine and absorption chiller is convenient also considering an important increase in the price of natural gas (up to $0.06 € / \mathrm{kWh}$, i.e., $+61 \%$ ).

From the economic point of view, the inclusion of the CHP engine only (configuration 1 in Figure 10) results in a lower payback time due to lower installation costs compared to configuration 2 (the purchase and installation costs of the absorber is no more considered) and a quite similar reduction in operating costs $(-32 \%)$.

On the other hand, these best options in terms of profit and energy efficiency obtain similar or lower shares of renewable energy utilization of the basic configuration (12-18\% versus $18 \%$ of the basic configuration), which is obtained thanks to the contribution of the two existing photovoltaic power stations and the average contribution of renewables in the Italian electric systems. The lower share $(12 \%)$ is due to the self-production of electricity in the CHP engine (totally from a non-renewable source) which reduces the consumption of electricity taken from the grid (partly generated from renewable sources).

A significant increase of the renewable share can be achieved by replacing the existing natural gas-fueled boiler with a boiler fed by pruning residues from the vineyard, while it is not possible to further increase the contribution of the photovoltaic because there is not sufficient availability of surface area neither on the cellar roof nor close to the cellar for a ground mounted installation.

The amount of biomass required to cover only the thermal energy requirements of the cellar (configuration 3 in Figure 13) is about half of the yearly available biomass (400 tons), and the remaining half can be left for composting. The maximum share of renewable can be obtained by operating this configuration according with the minimization of primary energy consumption from fossil fuels, and is about $31 \%$. On the other hand, the energy utilization of the biomass can be increased (up to the total exploitation of available biomass) by including also an absorption chiller fed by the thermal energy generated in the biomass boiler (configuration 4 in Figure 12). This is the best option in terms of share of renewable energy utilization, and the maximum achievable annual share (considering the contribution of photovoltaic, electricity from renewables taken from the grid and biomass) is equal to $35 \%$.

These two options are currently not economically attractive (negative net presents value at 25 years) due to the high investment costs required by the biomass utilization chain. However, configuration 3 may become interesting from an industrial point of view (payback time of the order of 10 years) when the price of natural gas increases of at least $50 \%$. 
Although all the calculations were performed using data from a reference Prosecco wine cellar, the results obtained here provide reliable indications for the design of the energy system of other wine cellars aimed at increasing either the renewable energy utilization share or the profit and/or the efficiency. Moreover, the developed model has general characteristics and can be therefore applied in cellars different from the reference one, where the available data are reasonably of the same type.

Other complementary issues were addressed in developing this work and could be topics for further developments in the search for the best utilization of all the resources required by the wine cellar. The more relevant are:

- The reduction of water consumption, which is of particular importance for a more sustainable wine-making process, especially in areas with low water availability (usually a cellar requires $7 \mathrm{~L}$ of water for $1 \mathrm{~L}$ of produced wine) [33,34]. This is not the case of the considered Prosecco cellar, as demonstrated in the preliminary work performed by the first author in [35].

- The recovery of $\mathrm{CO}_{2}$ from the fermentation processes, an innovative technique that allows obtaining $\mathrm{CO}_{2}$ at high level of purity. This technique can be applied to reduce the $\mathrm{CO}_{2}$ emissions and, at the same time, to use this gas for other purposes in the cellar, as shown in $[1,36]$.

Author Contributions: Conceptualization, all authors.; methodology, S.R. and D.P.; software, D.P. and S.R.; validation, D.P.; formal analysis, D.P. and A.L.; investigation, resources, data curation, D.P.; writing-original draft preparation, all authors; writing - review and editing, all authors; visualization, D.P. and S.R.; supervision, A.L. and S.R. All authors have read and agreed to the published version of the manuscript.

Funding: This research received no external funding.

Acknowledgments: The authors thank the entire staff of EsPiù S.R.L. for having supported the study with data and technical information. The authors are also grateful to the company Borgo Molino Vigne\&Vini who made available the know-how in the wine-making sector.

Conflicts of Interest: The authors declare no conflict of interest.

\section{References}

1. Creo, C.; Ansanelli, G.; Buttol, P.; Chiavetta, C.; Cortesi, S.; Cutaia, L.; Nobili, P.; Sposato, P. Uso Efficiente delle Risorse nelle Imprese Vitivinicole; National Agency for New Technologies, Energy and Sustainable Economic Development: Roma, Italy, 2018; ISBN 9788578110796.

2. Intelligent Energy Europe TESLA European Project (Tranferring Energy Save Laid on Agroindustry). Available online: https://ec.europa.eu/energy/intelligent/projects (accessed on 1 July 2019).

3. D'Amico, M.; Basile, G.C.S. Best Practice e Indicatori Ambientali delle Organizzazioni Vitivinicole Italiane Registrate EMAS; Mazzella, D., Ed.; ISPRA: Roma, Italy, 2016; ISBN 9788844807719.

4. Santolini, E.; Barbaresi, A.; Torreggiani, D.; Tassinari, P. Numerical simulations for the optimisation of ventilation system designed for wine cellars. J. Agric. Eng. 2019, 50, 180-190. [CrossRef]

5. Nocera, F.; Caponetto, R.; Giuffrida, G.; Detommaso, M. Energetic retrofit strategies for traditional sicilian wine cellars: A case study. Energies 2020, 13, 3237. [CrossRef]

6. Arredondo-Ruiz, F.; Cañas, I.; Mazarrón, F.R.; Manjarrez-Domínguez, C.B. Designs for energy-efficient wine cellars (ageing rooms): A review. Aust. J. Grape Wine Res. 2020, 26, 9-28. [CrossRef]

7. Benni, S.; Maria, F.D.; Barbaresi, A.; Torreggiani, D.; Tassinari, P. Wine cellar modeling for the assessment of energy efficiency. Int. Conf. Agric. Eng. 2014, 2014, 6-10.

8. Malvoni, M.; Congedo, P.M.; Laforgia, D. Analysis of energy consumption: A case study of an Italian winery. Energy Procedia 2017, 126, 227-233. [CrossRef]

9. Fuentes-Pila, J.; García, J.L. Manuale Sull'Efficienza Energetica nelle Aziende Vinicole; Universidad Politécnica de Madrid: Madrid, Spain, 2014.

10. ISPRA (Istituto Superiore per la Protezione e la Ricerca Ambientale). Available online: www.isprambiente. gov.it (accessed on 1 July 2019). 
11. De Bortoli, M. La Sostenibilità Ambientale nel Settore Vitivinicolo. Master's Thesis, Università Ca' Foscari, Venezia, Italy, 2013.

12. Paolino, S. Applicazione della Norma UNI CEI EN ISO 50001 Alle Cantine Vinicole; Politecnico di Torino: Turin, Italy, 2018.

13. Catrini, P.; Panno, D.; Cardona, F.; Piacentino, A. Characterization of cooling loads in the wine industry and novel seasonal indicator for reliable assessment of energy saving through retrofit of chillers. Appl. Energy 2020, 266, 114856. [CrossRef]

14. Gómez-Lorente, D.; Rabaza, O.; Aznar-Dols, F.; Mercado-Vargas, M.J. Economic and environmental study of wineries powered by grid-connected photovoltaic systems in Spain. Energies 2017, 10, 222. [CrossRef]

15. Fernández-Puratich, H.; Hernández, D.; Tenreiro, C. Analysis of energetic performance of vine biomass residues as an alternative fuel for Chilean wine industry. Renew. Energy 2015, 83, 1260-1267. [CrossRef]

16. Spinelli, R.; Lombardini, C.; Pari, L.; Sadauskiene, L. An alternative to field burning of pruning residues in mountain vineyards. Ecol. Eng. 2014, 70, 212-216. [CrossRef]

17. Albergucci, M. Logistics of Vine-Shoots Harvesting in Treviso Province. Master's Thesis, University of Padua, Padova, Italy, 2011.

18. Bacenetti, J. Heat and cold production for winemaking using pruning residues: Environmental impact assessment. Appl. Energy 2019, 252, 113464. [CrossRef]

19. Zanetti, M.; Brandelet, B.; Marini, D.; Sgarbossa, A.; Giorio, C.; Badocco, D.; Tapparo, A.; Grigolato, S.; Rogaume, C.; Rogaume, Y.; et al. Vineyard pruning residues pellets for use in domestic appliances: A quality assessment according to the EN ISO 17225. J. Agric. Eng. 2017, 48, 99-108. [CrossRef]

20. Pizzi, A.; Foppa Pedretti, E.; Duca, D.; Rossini, G.; Mengarelli, C.; Ilari, A.; Mancini, M.; Toscano, G. Emissions of heating appliances fuelled with agropellet produced from vine pruning residues and environmental aspects. Renew. Energy 2018, 121, 513-520. [CrossRef]

21. Picchi, G.; Silvestri, S.; Cristoforetti, A. Vineyard residues as a fuel for domestic boilers in Trento Province (Italy): Comparison to wood chips and means of polluting emissions control. Fuel 2013, 113, 43-49. [CrossRef]

22. Ito, K.; Yokoyama, R.; Shiba, T. Optimal operation of a diesel engine cogeneration plant including a heat storage tank. J. Eng. Gas Turbines Power 1992, 114, 687-694. [CrossRef]

23. Ito, K.; Yokoyama, R.; Akagi, S.; Yamaguchi, T.; Matsumoto, Y. Optimal operational planning of a gas turbine combined heat and power plant based on the mixed-integer programming. IFAC Proc. Ser. 1989, 21, 371-377. [CrossRef]

24. Christidis, A.; Koch, C.; Pottel, L.; Tsatsaronis, G. The contribution of heat storage to the profitable operation of combined heat and power plants in liberalized electricity markets. Energy 2012, 41, 75-82. [CrossRef]

25. Rech, S.; Lazzaretto, A. Smart rules and thermal, electric and hydro storages for the optimum operation of a renewable energy system. Energy 2018, 147, 742-756. [CrossRef]

26. D.Lgs. n. 152 del 3/04/2006. Allegato X. Available online: www.gazzettaufficiale.it (accessed on 1 July 2019).

27. Maya Air Conditioning. Available online: www.maya-airconditioning.com (accessed on 1 July 2019).

28. Viessmann. Available online: www.viessmann.it (accessed on 1 July 2019).

29. Peruzzo. Available online: www.peruzzo.it (accessed on 1 July 2019).

30. Cover Technology. Available online: www.covertechnology.it (accessed on 1 July 2019).

31. Rech, S. Smart energy systems: Guidelines for modelling and optimizing a fleet of units of different configurations. Energies 2019, 12, 1320. [CrossRef]

32. GSE. Available online: www.gse.it (accessed on 1 July 2019).

33. Novelli, E.; Lamastra, L.; Trioli, G. Sostenibilità in cantina: La gestione dell'acqua. L'Inf. Agrar. 2014, 11, 1-4. Available online: https://www.researchgate.net/publication/262723168_Sostenibilita_in_cantina_la_gestione_ dell\%27acqua (accessed on 25 November 2020).

34. Novelli, E. Razionalizzare IConsumi Di Acqua in Cantina. Vigne Vini \& Qualita. 2017, pp. 17-18. Available online: http://www.viticolturasostenibile.org/Downloads/VQ_Acqua\%202017.pdf (accessed on 25 November 2020). 
35. Pivetta, D. Energetic, Economic and Environmental Analyses of the Energy Consumption of a Winery. Master's Thesis, University of Padua in Energy Engineering, Padova, Italy, 2019.

36. Vicenzi, N.; Bussola, F. IL Recupero della CO2 di Fermentazione. MilleVigne. 2013, Volume 1. Available online: http://www.viten.net/files/d6d/d6def1c7bdc441b61e9f82a986286ca3.pdf (accessed on 25 November 2020).

Publisher's Note: MDPI stays neutral with regard to jurisdictional claims in published maps and institutional affiliations.

(C) 2020 by the authors. Licensee MDPI, Basel, Switzerland. This article is an open access article distributed under the terms and conditions of the Creative Commons Attribution (CC BY) license (http://creativecommons.org/licenses/by/4.0/). 